\title{
A CLASSIFICATION AND REVIEW OF APPROACHES AND METHODS FOR MODELING UNCERTAINTY IN PROJECTS
}

\author{
Öncü Hazıra ${ }^{\mathrm{a}}$, Gündüz Ulusoy ${ }^{\mathrm{b}}$ \\ ${ }^{a}$ Rennes School of Business, Rennes, France \\ ${ }^{b}$ Sabanci University, Faculty of Engineering and Natural Sciences, Istanbul, Turkey
}

\begin{abstract}
In this paper, we created a classification for major sources of uncertainty in projects and categorized the studies in project scheduling literature with respect to the uncertainty source(s) they address. In addition, we investigated the approaches and methods to manage uncertainty, and studied the literature regarding these methods. Project management predominantly models the randomness in duration of activities; however, studies modeling the uncertainty due to other sources are scarce. We focused on these sources of uncertainty and highlighted the promising areas of research. The results presented in this paper will help researchers to identify the research gaps in modeling project uncertainty.
\end{abstract}

Keywords: Project Management, Project Scheduling, Uncertainty, Stochastic Scheduling, Robust Scheduling, Reactive Scheduling

\section{INTRODUCTION}

With the change in the business paradigm over recent decades, projects have become another major way of doing work in today's organizations alongside other processes. During the recent phase of industrial organization, constant change has become the fundamental rule of the game, and implementing change is usually organized through projects (Pich et al., 2002). Recently we have also observed an increase in the number of organizations that structure themselves as project organizations, such as in engineering, managerial and financial services companies and in technology firms. In any type and size of organization, it has become common practice to organize tasks as projects. This may be considered as a result of contemporary management practices, which have changed from a hierarchical and centralized nature to a more flat and decentralized one. Another factor that has affected private enterprises is the increasing competitive pressure that forces them to seek excellence in accomplishing the tasks. In this regard, organizing the tasks as projects serves to facilitate control, coordination and communication (Meredith and Mantel, 2005). Due to all these developments and advantages, organizations have become more project-driven and project management practices have become more critical.

The final version published in International Journal of Production Economics, 223, May 2020 https://doi.org/10.1016/j.ijpe.2019.107522. 
All projects are subject to various uncertainties. During the execution phase, various problems such as inaccurate time estimates, procurement delays, authorization delays and disruptions, such as machine failures, may be encountered and they may make it more difficult to achieve the targets. All these examples represent circumstances where the decision makers, mostly the project managers, have "only partial information about the situation or outcomes" (Meredith and Mantel, 2005). This lack of complete information is an inevitable part of managerial decision making, and methods to handle uncertainty need to be developed. In their survey of 60 years of project management research, Padalkar and Gobinath (2016) concluded that empirical and deterministic perspectives dominate research, whereas research on non-deterministic methods remains weak and sporadic.

Uncertainty in projects is classified in published literature mostly either by the source or the impact (Pich et al. 2002). Miller and Lessard (2001) roughly divided the types of uncertainties that arise in project management into three categories: market-related, such as demand, competition and the supply chain; completion related, such as technical, construction and operational; and institutional, such as regulatory, cultural and extranational. Focusing on the sources, Leifer et al. (2001) list four main groups: technical, market, organizational and resource uncertainties. Ward and Chapman (2003), on the other hand, name five: variability associated with estimates, uncertainty about the basis of the estimates, design and logistics, objectives and priorities, and fundamental relationships between project stakeholders. They suggest a move from project risk management towards project uncertainty management and emphasize the need to understand the origins of uncertainty before attempting to manage it. Atkinson et al. (2006) underlined that a necessary condition for effective project management is the management of uncertainty. They highlighted the association of the sources of uncertainty with the estimation, project participants, and stages of the project lifecycle.

Pich et al. (2002) emphasized managerial approaches and listed four types of uncertainty in projects: variation, foreseen uncertainty, unforeseen uncertainty and chaos. In their thinking, variation refers to the random deviations that have small impacts. One commonly encounters such random deviations in every project. Chaos, on the other hand, happens rarely but creates great impact on project targets. Each type requires a different planning and control approach. In this regard, Huchzermeier and Loch (2001) underlined the value of managerial flexibility, specifically in managing $R \& D$ projects. They interchangeably used the terms uncertainty and variability, and focused on five types of variability: variability in market payoffs, budgets, product performance, market requirements and schedules. They modeled 
the relationship between these uncertainty types and the economic value of managerial flexibility, such as expanding or abandoning the project, using real options theory.

Concerning the impacts on project goals, Zhu et al. (2005) divided project uncertainty into two main groups: small deviations and disruptions. Deviations are commonly encountered as a result of random variations, particularly in the duration of activities. On the other hand, disruptions are rare, unexpected events, such as the occurrence of natural disasters or the unexpected departure of key team members. They are much more difficult to manage. The authors classified these disruptions according to their effect on the project structure:

- Project network disruptions: New activities or precedence relations may be added or deleted in the network.

- Activity disruptions: Activity times or resource demands of the activities may change.

- Resource disruptions: Resource availability may change.

We note that there are review papers on project management about uncertainty. Herroelen and Leus (2004) investigated the work on robust (proactive) and reactive project scheduling. In their further work, Herroelen and Leus (2005) grouped together and reviewed approaches for scheduling under conditions of uncertainty. They investigated these approaches under five headings: reactive scheduling, stochastic project scheduling, fuzzy project scheduling, robust scheduling and sensitivity analysis. Atkinson et al. (2006) focused on sources of uncertainty based on the results of a two-year study. They concluded that common practice in project management tends not to address many fundamental sources of uncertainty. This is particularly true in the conception and post-delivery stages of the project lifecycle or in "soft" projects where flexibility and tolerance of vagueness are necessary, and which emphasize the need for more sophisticated efforts to recognize and manage important sources of residual uncertainty. Recently, Vale and Carvalho (2017) presented a review that addressed risk and uncertainty in project management, especially in the context of innovation management. Hazir (2015) and later Pellerin and Perrier (2018) reviewed project monitoring and control studies. Ortiz-Pimiento and Diaz-Serna (2018) focused on uncertainty in activity durations within different problem settings, and on scheduling algorithms.

Different from the review papers above, we investigated both the sources of uncertainty addressed, their classification together with their impact of uncertainty on project goals, and the management approaches adopted in published literature for mitigating the impact of uncertainty. We focused on project scheduling similar to the reviews of Herroelen and Leus, but differently in that we examined the literature from the perspective of sources of uncertainty In addition, we integrated the papers published over the last 20 years. We believe 
that it is valuable to explore the recent approaches and trends, and summarized the progress in academic knowledge in this area.

We summarized the contributions of this review study as follows: First of all, the classification of the sources of uncertainty is comprehensive and detailed. The reviews on sources of uncertainty and managing approaches cover the recent studies and examine the current research directions. In this regard, the review will help researchers to identify the research gaps in developing project plans under uncertainty. The results summarized might serve as a useful base for investigating and modeling the characteristics of various sources of uncertainty and their impacts on achieving project targets. In addition, the discussions might work as a basis for developing decision support systems (DSSs) that aid project managers to plan in uncertain environments.

The paper is organized as follows: section 2 reports on the sources of uncertainty in projects and provides a classification of these sources under two main categories: (i) internally generated and (ii) externally generated. Under each category, subcategories of sources of uncertainty are defined and papers investigating those subcategories are reviewed. The papers cited in section 2 are then listed in a table with the subcategory/subcategories of the sources of uncertainty indicated for each paper, thus associating each subcategory to the corresponding references. In section 3 we investigated five fundamental scheduling approaches to manage project uncertainty. These approaches are stochastic scheduling, fuzzy scheduling, sensitivity analysis, reactive scheduling and robust scheduling (Herroelen and Leus, 2005). Taxonomy of the papers based on these approaches is presented in a summary table. Section 3 concludes with a critical analysis of the approaches. A number of conclusions and research directions are provided in section 4 .

\section{SOURCES OF UNCERTAINTY IN PROJECTS}

We first classified the uncertainty into two broad categories with respect to the way the project is organized: internally and externally generated. Then more specific subcategories are defined. Figure 1 summarizes our classification scheme. Internally generated uncertainties relate to systems and resources that can directly be associated with the project, and they can largely be controlled by the organization. However, many other uncertainties are caused by factors external to the project and hence, cannot be controlled by the organization. These are considered to be externally generated uncertainties. 
We note that it is difficult to make a clear distinction between internal and external sources of uncertainty in many cases since the factors causing uncertainty often interact with, or trigger, each other. For example, changes in market conditions or economic parameters are externally generated. Project managers cannot control them but such changes can cause managers to reconsider project priorities, which are internally defined organizational factors. In addition, economic uncertainty can affect the budgets and resource availability. In the following section, subcategories are discussed in detail.

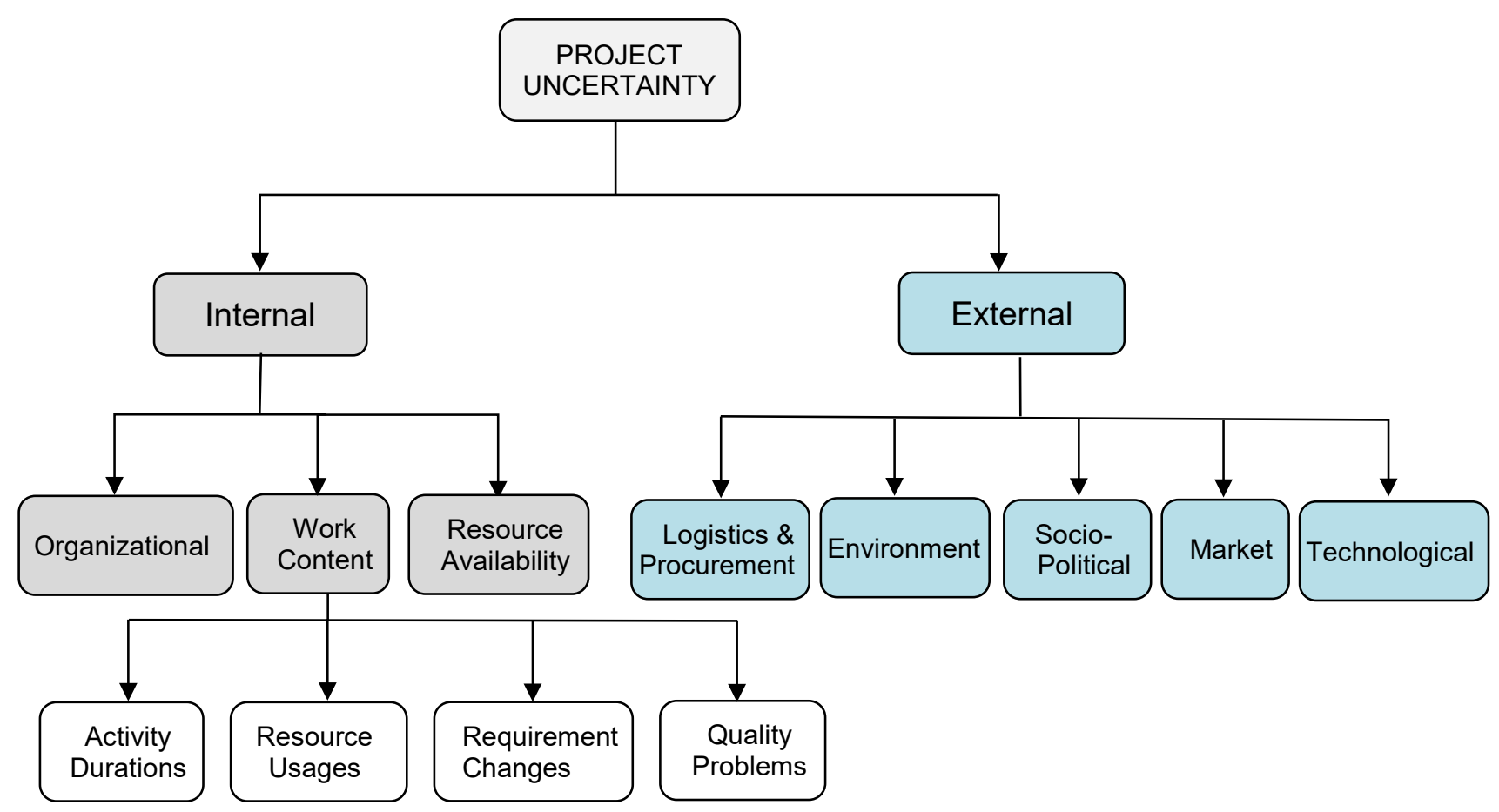

Figure 1: Project Uncertainty Sources and Their Classification

\subsection{Internally Generated Uncertainties}

These are the factors that are directly related to the project and are, to a large extent, controlled by the organization. We classified them as factors related to the organization, work content and resource availability.

\subsubsection{Organizational}

The objectives and priorities of the organizations, their structure, managerial approaches, responsibilities and management authority, communication channels and relations with stakeholders and other organizations are the factors that significantly affect the success of the projects. Considering the organizational factors, Petit (2012) investigated how uncertainty affects the project portfolios and develops a conceptual framework that includes the environment, strategy, organizational structure, constraints, corporate governance and project portfolio characteristics. 
Ward and Chapman (2008) focused on the project stakeholders, whom they considered to be a major source of uncertainty, and make a detailed analysis on the uncertainties stemming from the stakeholders. They proposed a generic project uncertainty management framework to employ in order to analyze stakeholders and related uncertainty management issues. They concluded that for a systematic approach to stakeholder management, project uncertainty differing management processes would be needed in the stages of the project lifecycle.

Petit and Hobbs (2010) reported an empirical study investigating the management of project portfolios in dynamic environments. Organizational factors might change during the execution of the projects. Following these changes, the contracting organization might also reassess its objectives and priorities regarding these projects. To give an example, a specific project might be re-prioritized, more resources could be allocated to the project, and the project manager might be asked to speed up the project delivery. Communicating this timebased objective, and revising the project strategy and plans becomes an important task for the project manager.

Jorgensen and Wallace (2000) dealt with the interaction of project cost estimation and managerial flexibility. In this context, they defined managerial flexibility as the ability or option to make changes as the project is running. They indicated that a static deterministic model leads on average to lower costs than the actual cost; whereas, a static, stochastic model results on average in higher costs than the cost of applying an optimal dynamic strategy. The project managers exercising managerial flexibility often update the schedules during the execution of the project by rerunning the static model to reduce the expected cost. Jorgensen and Wallace designated the expected cost reduction as the value of flexibility. They proposed a simulation-based algorithm for obtaining an estimate of the expected total cost.

Dealing with multiple projects simultaneously can be a source of complexity in organizations. In multi-project organizations, the over commitment of resources and faulty scheduling decisions can result in unjustified resource deficiencies in other projects. This can lead to uncertainties in resource management (Engwall and Jerbrandt, 2003).

The initial and critical step in project planning is defining the requirements and the work content, and then breaking the work content into manageable work packages. 


\subsubsection{Work Content (WC)}

From the operations management perspective, project management emphasis is given to defining the goals, mostly expressed as time or cost-based targets, creating the work breakdown structure (WBS) and scheduling the activities to attain these goals. Most of the scheduling studies either assume deterministic project parameters or only activity durations as random. In fact, the work content, which could broadly be defined as the effort required for completing all the project activities, is random (Tereso et al., 2004a; Elmaghraby, 2005). The required effort to perform an activity can broadly be calculated by multiplying the amount of resource use and the activity duration, and expressing it in units of man-hours or machine-hours. These two variables are dependent and activity time varies with the amount of resources allocated. As a result, activities can be performed in different modes where each corresponds to processing with different technologies or resource assignments, and hence with a different time and cost setting.

The work content approach focused on the variability of the overall effort instead of analyzing the variables separately. The required effort was estimated and the activity durations were modeled as a consequence of resource allocations, not as a separate source of uncertainty (Tereso et al., 2004a; Elmaghraby, 2005). We reviewed both approaches, i.e., the studies that investigated the components of the work content individually as either resource use or activity duration, and jointly as the work content.

Tereso et al. (2004a) associated randomness to the work content of each activity. The resources assigned to an activity can be subject to randomness or might be deterministic. Activity duration is determined by its work content and the resources allocated. They considered only one resource and took the resource allocation for each activity to be a deterministic decision variable defined within a specified interval. The total cost is the sum of the resource cost and the tardiness cost. The dynamic programming (DP) approach they proposed is applicable to any probability distribution of the work content of the activities. Because of the computational burden of the DP model, they proposed two approximation schemes. Tereso et al. (2004b) applied the electromagnetism approach (EMA) of Birbil and Fang (2003), and later, Tereso et al. (2007) suggested an evolutionary algorithm (EVA) approach for further computational improvement. An extension to multiple resources is provided by Tereso et al. (2008). They employed DP, EMA and EVA, where EVA turns out to be the most promising solution procedure.

In many projects activity durations deviate from the estimates. Activities usually take more time or require more resources than planned due to inaccurate estimation of these variables, 
and/or unexpected events faced during execution. Sometimes rework might be required. In all these cases the amount of effort spent increases. In some other cases, it might be necessary to change the processing sequence of the activities, mainly due to the changes in technical requirements. Such changes require altering the project network and time planning. Considering all these cases, we classified the major factors that create uncertainty in the work content into four groups: the activity durations, resource use, requirement changes and quality problems.

- Activity Durations: Inaccurate estimation is the major source of deviation in activity durations.

- Resource Use: The quantity of resources to complete a particular activity might not be correctly predicted.

- Requirement Changes: Changes in organizational or customer requirements, or in technical processes, might lead to changes in the work content. As a result, the project network might need to be modified. Also, new activities or precedence relations might be added into, or deleted from, the project network. Deadlines might also change.

- Quality Problems: Rework might be needed due to quality problems, in which case there may be delays.

Lack of clear specifications, expertise or in-depth analysis and the complexity of the estimation process are the principal sources of inaccurate estimates, both in activity durations and in use of resources (Ward and Chapman, 2003). In addition to estimation problems, project managers often face quality problems. On the other hand, changes in customer requirements usually result in scope deviations and a need for re-planning. All these cases mean redefining the project parameters: the activity durations, resource requirements, quality requirements, precedence relations and the project network. Next, we summarized the studies that focused on the uncertainty in these parameters. We will investigate the studies that address the randomness in activity durations in section 3.3 on stochastic project scheduling. In this section, we focused on the remaining three types of uncertainty.

When deviations from the baseline plan are observed and are judged to threaten the completion of these activities on time, project managers usually allocate extra resources such as additional workers or extra machinery to these activities. This creates fluctuations in the amount of resources allocated to each activity and variability in total resource usage. Nozick et al. (2004) considered this variability. They considered that the mean and/or the variance of durations might decrease with resource allocations and proposed a nonlinear mixed integer program to schedule the projects to minimize the total resource investment. Note that 
employing additional resources to reduce activity durations, namely project crashing, also results in cost uncertainty.

Tavares et al. (1998) modeled the randomness in both the cost and duration of activities, and optimized the discounted cost of the project and the risk of not meeting the deadline. Hazir et al. (2011) addressed the trade-off in time and cost, and formulated optimization models in which interval uncertainty is assumed for the unknown cost parameters. Likewise Gutjahr (2015) addressed multi-mode scheduling and modeled both duration and cost as random variables. Maravas and Pantouvakis (2012) modeled the uncertainty in cost and duration using fuzzy numbers. Considering the uncertainty in costs, as well in duration, due date and budget, Jeang (2015) investigated the impact of learning by using simulation and statistical analysis. Zhang and Elmaghraby (2014) dealt with the financial management of projects under uncertainty, where the duration and cost of activities are random variables and hence, the cumulative cost at each time point becomes a random variable. They approached the issues involved in relation to the Earned Value Method. Through scenario analysis, using Monte Carlo sampling and Gantt chart analysis, they developed an envelope around the cumulative cost at any point throughout the project duration. They employed multiple methods of expenditure in activities and two payment models: (i) payments made according to a fixed time schedule, and (ii) payments made at milestone events. They concluded that the financial status over the project duration is not affected by the activities' duration distribution or the choice of cost function, but is greatly affected by the payment schedule.

In many projects, scope changes are commonly encountered. Williams et al. (1995) addressed design changes and examined the effects on project costs. These changes might require project networks to be redrawn. In this regard, Artigues and Roubellat (2000) proposed an algorithm to insert new activities into the project network with general precedence relations in a resource constrained problem setting with multiple modes and cumulative constraints. They minimized the effect of the insertion on maximum lateness. Artigues et al. (2003) present a polynomial insertion algorithm based on which they propose scheduling algorithms for the static resource-constrained project scheduling problem (RCPSP) and for rescheduling in a dynamic RCPSP setting with the objective of minimizing the resulting makespan. Özdamar and Alanya (2001) examined software development projects and considered uncertainty in both task durations and in network topology, specifically start-to-start precedence relationships among activities. These network changes are mainly caused by the common use of database and program modules, and design problems might result from changes in precedence relations. Recently, Vaagen et al. (2017) investigated the complexity in planning engineer-to-order projects due to design uncertainty, 
which covered changes in specifications. Uncertainty in technical information also brings uncertainty in the project network. To manage this uncertainty, they proposed developing activities that are common in alternative designs, and postponing design-specific decisions.

Bordley et al. (2019) focused on contract related uncertainties, specifically the deadline uncertainties, which are usually due to changes in requirements. Changes in the deadline might result from stakeholder requests or internal units. Failures in certain activities might cause inevitable delays. Deviation from the deadline might lead to penalties (tardiness cost) or bonuses. Regarding this, Estevez-Fernandes (2012) introduced a theoretical gaming approach to share the penalties as well as the rewards within projects.

Even though the quality of the project deliverables is one of the three major performance criteria - together with project cost and duration - the majority of the studies do not explicitly address quality. This is indeed an unexpected observation considering that Tukel and Rom (2001) reported in their empirical study conducted in the USA, that quality, as the primary measure of success for project managers over all stages of a project and meeting customer needs, was their primary objective. Quality requirements affect the effort required or more broadly the work content. In this regard, Tukel and Rom (1997) developed mixed integer programming models to minimize the rework time and rework cost in an RCPSP setting. Rework is shown to have an impact on project completion time and project budget, particularly in projects with relatively higher complexity.

Kim et al. (2012) defined individual activity quality as the conformance to a project contractor's requirements. Non-conformance required rework or modification. They proposed a mixed integer linear programming (MILP) model to solve the time-cost tradeoff problem by considering the potential quality loss cost resulting from excessive crashing besides the actual crashing cost. They did not assign a grade against nonconformance to an activity but assumed conformance and nonconformance as the only two states, which they claimed were of more practical relevance, since contractors do not usually accept quality degradation. Models considering quality levels, on the other hand, were proposed by Babu and Suresh (1996), and Tareghian and Taheri (2006, 2007).

Tiwari et al. (2009) considered a multi-project environment where projects are separate and independent but require the same resource mix. Here the workforce is of heterogeneous skill levels that can perform work on more than one activity but at different skill/quality levels. This can lead to variations in the quality of the end products/services. Depending on the individual or the team assigned to perform a task, rework might be required afterwards by 
another individual or team with different skill levels. They formulated the problem as a multi-mode, resource-constrained project scheduling problem (MRCPSP) with the objective being the minimization of the makespan but with acceptable activity quality levels secured through rework. The model can be employed to demonstrate the bottlenecks for critical resource skills and the advantages of having a flexible workforce; hence the need for cross training.

\subsubsection{Resource Availability}

A major source of uncertainty in the availability of resources is caused by breakdowns. Even though breakdowns have been commonly studied in machine scheduling (Aytug et al., 2005), studies addressing the uncertainty in availability of resources in project scheduling are scarce. Focusing on renewable resources, Lambrechts et al. (2008a, 2011) developed procedures to generate robust schedules, and Lambrechts et al. (2008b) integrated rescheduling procedures to recover after a disruption. Fu et al. (2015) aimed to predict the effect of resource breakdowns and repairs, and improving the robustness of resource allocations. In contrast, Deblaere et al. (2011a) focused on reactive scheduling to recover from disruptions in both non-renewable and renewable resources.

Regarding the availability of resources, cash-flow planning is vital in projects. There are many studies that model cash flows and optimize financial objectives; mostly the net present value (NPV). The majority of them assume that the timing and amount of flows are known; however, there are only a few that address the inherent uncertainty. Boute et al. (2004) investigated the real options approach, which created the flexibility to adapt a response to newly available information. Wiesemann et al. (2010) maximized the expected NPV of a project by considering a discrete set of alternative scenarios, which corresponded to the realization of the uncertain variables: activity durations and cash flows. Sobel et al. (2009) formulated dynamic programming models based on the continuous-time Markov chain to schedule a project so as to maximize the expected NPV for a project setting where the client and the contractor are the same. They took into account uncertainty in activity durations, costs and revenues.

Yang and Chang (2005) investigated the uncertainty in the supply of resources and funding in repetitive construction projects. Having defined the supply of resources and funding as random variables, they converted the associated stochastic constraints to their respective deterministic equivalents for solving the model with chance-constrained programming (CCP). The underlying assumption was that the availability of all the resources and funding was independent. They applied the model to a housing project comprising 100 units of 
housing and verified the solution by Monte Carlo simulations. The deterministic solution obtained using the mean values for the variables resulted in an optimistic solution compared to the CCP solution.

Maintaining cash availability throughout the project is crucial for the project manager to prevent any discontinuity in cash flow. An objective along those lines would be the minimizing the contractor's maximum cumulative gap between cash out and cash in. Ning et al. (2017) investigated this problem in a multi-mode setting with stochastic activity durations. They solved the problem using two different metaheuristic procedures and reached the following conclusions: the problem of capital shortage can be addressed by inserting time buffers properly and choosing less expensive activity modes.

Özdamar and Dündar (1997) and Özdamar (1998) focused on financial risks, particularly in housing construction projects. In addition to integrating the uncertainty in cash flows, they also considered multiple modes for performing the activities. Recently, Hazir et al. (2016) addressed financial risks as well and examined the delays in payments by the client firms. The model featured delays that are dependent on the financial structure of the clients and that these delays could significantly alter the NPV of the projects. Regarding the risks, budgeting is crucially important for projects. Existing studies usually assume a known static project budget; however, the funds to support the project might deviate from the original estimate during execution. Firms control many projects and consider various financial alternatives at the same time. Therefore addressing the budget uncertainty is important. In his model, Yang (2005) characterized the budget as a random variable in a time-cost tradeoff problem setting, and solved the problem using CCP. A higher degree of uncertainty was shown to represent a tighter financial constraint resulting in extra contingency duration.

\subsection{Externally Generated Uncertainties}

Externally generated uncertainties mainly contain logistics and procurement, environmental, socio-political, market, and technological factors. 


\subsubsection{Logistics and Procurement Factors}

Variability in procurement lead times and disturbances due to problems with suppliers are commonly encountered in projects. Availability and on-time delivery of materials, equipment and labor during a project lifecycle can seriously affect the project delivery. Recently many firms favor the use of subcontractors and the procurement process has become more complicated and contains more uncertainty. Problems in coordinating the work between different subcontractors can cause delays to the project delivery.

Yeo and Ning (2006) focused on the problems of uncertainty and variation in major equipment procurement. They conducted a survey to explore time uncertainty in the procurement of major equipment and explored the relationship between time buffers and procurement lead times. Dixit et al. (2014) used fuzzy integer programming to model uncertainty in activity durations and in lead times.

$\mathrm{Xu}$ et al. (2016) integrated project and supply chain management decision making in recurrent projects. They focused on the construction industry and addressed uncertainty in procurement lead times. They used dynamic programming for modeling the integration problem and conducted sensitivity analysis to show the impact of uncertainty. Likewise, Liu et al. (2017) addressed uncertainty in construction supply chains, but instead, made use of multi-objective optimization and fuzzy theory for modeling.

\subsubsection{Environmental Factors}

For some industries, the impact of natural events and environmental concerns is vital. For instance, in the construction industry, weather conditions are one of the main causes of project delays and the need for rescheduling. Acabes et al. (2014) focused on the uncertainty due to seasonal factors, such as any meteorological factors or adverse weather conditions that might affect completion of the activities. Using Monte Carlo simulation and sensitivity analysis, they investigated how activities contributed to project risks, specifically the risks of delays in project delivery.

We also noted that in some cases, abandoning the projects could be a logical decision. To give an example, for some mega construction projects, environmental damage might not be fully predicted, or the social and financial impacts could have been underestimated, at the investment phase. In project assessments, real options theory has been widely implemented. It allows integration of the possibility of abandoning a project due to a catastrophic event (see Schwartz \& Zozaya-Gorostiza (2003), for an IT investment decision). 


\subsubsection{Socio-Political Factors}

Laws and regulations, and political and social pressures, are among the elements of the environment in which the project lifecycle takes place and which can change over time. For example, changes in health and safety regulations, or government environmental or taxation policy might affect the attainment of project targets.

Al-Tabtabai and Alex (2000) focused on political risks in international construction projects and developed a neural network model to estimate the impacts of political uncertainty on project cost. Klastorin and Mitchell (2013) considered a broad range of events that could disrupt the ordinary course of projects. These events included social or political events, such as strikes and regulatory actions. In their model, they assumed that such a disruptive event would stop all direct labor-related work on the project for a specific time period, but that overheads and indirect work would continue, and these expenses would accrue.

\subsubsection{Market Factors}

Market conditions, factor prices and demand may alter during the project execution. Fluctuations in the exchange rates and factor prices may cause uncertainty in costs. For instance, variations in material costs or exchange rates could have a serious impact on the total cost. This was demonstrated by Zhang et al. (2011) on how to select multinational projects under foreign exchange rate uncertainty. Petit and Hobbs (2010) studied new product development uncertainty. Due to high uncertainty inherent in the early stages of new product development, companies spend great effort on deciding on the features to develop for securing success in a market. A similar uncertainty arises in the case of make-or-buy decisions made in the earlier stages of new product development projects. Such market uncertainties can have an impact and also lead to uncertainties in their relations with suppliers.

\subsubsection{Technological Factors}

New process and product alternatives may emerge during the execution of the project. For instance, the introduction of new materials and methods during the execution of a project can change the project plan considerably.

Shenhar and Dvir (1996) classified projects into two dimensions: uncertainty and complexity. Under uncertainty, they focused on technological uncertainty and distinguished between four types: slow tech, medium tech, high tech and super high tech. Low tech projects such as road construction use existing technologies and well established methods, whereas super high tech projects depend completely on new technology. Concerning 
complexity, they differentiated between three levels: assembly, system and array. In assembly, a number of components are combined into a single unit. Systems consist of a collection of subsystems and interactive elements - built or developed - that perform a wide range of functions or activities. Arrays are defined as building, developing or adding to a large widespread collection of systems functioning together to achieve a common purpose. Shenhar (2001) concluded that project management techniques would differ across levels of uncertainty and complexity, and showed that uncertainty is associated with the way technical problems are resolved, whereas complexity is related to the administrative aspects of project management.

De Reyck and Leus (2008), and Creemers et al. (2015) addressed R\&D projects that face technological uncertainty, where in this context technological uncertainty refers to an environment where the project might fail as a consequence of the failure of an activity. They maximized the expected NPV of the project. De Reyck and Leus (2008) employed a branchand-bound $(\mathrm{B} \& \mathrm{~B})$ algorithm to achieve optimal solutions for an R\&D project with uncertain activity outcomes. Creemers et al. (2015) extended the work of De Reyck and Leus to include uncertain activity durations and the option of alternative technologies producing the same result. They employed stochastic dynamic programming to achieve optimal solutions. Ranjbar and Davari (2013) dealt with the alternative technology problem for R\&D projects, where each technology has a cost and a probability of failure. The objective was to maximize the expected NPV of the project. They proposed a branch-and-bound algorithm to solve the problem optimally.

\subsection{A Classification of Literature Based on Sources of Uncertainty}

We summarized the classification of literature based on sources of uncertainty in Table 1 . Papers only considering variability in activity durations are not included since there is a vast amount of literature on this. Our review revealed that studies addressing the uncertainty due to other sources are scarce. Resource-related variability, both in requirements and availability, has occasionally attracted the attention of researchers. Other sources of uncertainty have rarely been examined in project-planning studies. These sources of uncertainty should be addressed more often to model project environments more realistically and to generate schedules protected against various kinds of uncertainty. 
Table 1. Literature Analysis Based on Sources of Uncertainty *

\begin{tabular}{|c|c|c|c|c|c|c|c|c|c|c|c|}
\hline $\begin{array}{c}\text { Author(s) } \\
\text { (Ordered wrt Publication Year) }\end{array}$ & $\begin{array}{c}\text { Organizational } \\
\text { Factors }\end{array}$ & $\begin{array}{c}\text { Activity } \\
\text { Durations }\end{array}$ & $\begin{array}{l}\text { Resource } \\
\text { Usages }\end{array}$ & $\begin{array}{c}\text { Requirement } \\
\text { Changes }\end{array}$ & $\begin{array}{l}\text { Quality } \\
\text { Problems }\end{array}$ & $\begin{array}{c}\text { Resource } \\
\text { Availability }\end{array}$ & Logistics & $\begin{array}{c}\text { Nature \& } \\
\text { Environment }\end{array}$ & $\begin{array}{l}\text { Political } \\
\text { \& Social }\end{array}$ & Market & Technology \\
\hline Shenhar \& Dvir (1996) & & & & & & & & & & & $\mathbf{X}$ \\
\hline Tukel \& Rom (1997) & & & & & $\mathbf{X}$ & & & & & & \\
\hline $\begin{array}{l}\text { Ozdamar \& Dundar (1997), } \\
\text { Ozdamar (1998) }\end{array}$ & & & & & & $\mathbf{X}$ & & & & & \\
\hline Tavares et al. (1998) & & $\mathbf{X}$ & $\mathbf{X}$ & & & & & & & & \\
\hline Williams et al. (1995) & & & & $\mathbf{X}$ & & & & & & & \\
\hline Al-Tabtabai \& Alex (2000) & & & & & & & & & $\mathbf{X}$ & & \\
\hline Artigues \& Roubellat(2000) & & & & $\mathbf{X}$ & & & & & & & \\
\hline Ozdamar \& Alanya (2001) & & $\mathbf{X}$ & & $\mathbf{X}$ & & & & & & & \\
\hline Tukel \& Rom (2001) & & & & & $\mathbf{X}$ & & & & & & \\
\hline Artigues et al. (2003) & & & & $\mathbf{X}$ & & & & & & & \\
\hline Engwall \& Jerbrandt (2003) & $\mathbf{X}$ & & & & & & & & & & \\
\hline $\begin{array}{l}\text { Schwartz \& Zozaya- } \\
\text { Gorostiza (2003), }\end{array}$ & & & & & & & & $\mathbf{X}$ & & & \\
\hline Boute et al. (2004) & & & & & & $\mathbf{X}$ & & & & $\mathbf{X}$ & \\
\hline Nozick et al. (2004) & & $\mathbf{X}$ & $\mathbf{X}$ & & & & & & & & \\
\hline Yang (2005) & & & & & & $\mathbf{X}$ & & & & & \\
\hline Yang \& Chang (2005) & & & & & & $\mathbf{X}$ & & & & & \\
\hline Yeo \& Ning (2006) & & & & & & & $\mathbf{X}$ & & & & \\
\hline De Reyck \& Leus (2008) & & & & & & & & & & & $\mathbf{X}$ \\
\hline Lambrechts et al. (2008a) & & & & & & $\mathbf{X}$ & & & & & \\
\hline $\begin{array}{l}\text { Lambrechts et al. (2008b, } \\
\text { 2011) }\end{array}$ & & $\mathbf{X}$ & & & & $\mathbf{X}$ & & & & & \\
\hline Ward \& Chapman (2008) & $\mathbf{X}$ & & & & & & & & & & \\
\hline Sobel et al. (2009) & & $\mathbf{X}$ & & & & $\mathbf{X}$ & & & & & \\
\hline Tiwari et al. (2009) & & & & & $\mathbf{X}$ & & & & & & \\
\hline Petit \& Hobbs (2010) & $\mathbf{X}$ & & & & & & & & & $\mathbf{X}$ & \\
\hline Wiesemann et al. (2010) & & $\mathbf{X}$ & & & & $\mathbf{X}$ & & & & & \\
\hline Deblaere et al. (2011) & & $\mathbf{X}$ & & & & $\mathbf{X}$ & & & & & \\
\hline
\end{tabular}

*Studies that address only variability in activity durations are not included. 
Table 2. Literature Analysis Based on Uncertainty Sources * (Continued)

\begin{tabular}{|c|c|c|c|c|c|c|c|c|c|c|c|}
\hline Hazir et al. (2011) & & & $\mathbf{X}$ & & & & & & & & \\
\hline Zhang et al. (2011) & & & & & & & & & & $\mathbf{X}$ & \\
\hline Kim et al. (2012) & & & & & $\mathbf{X}$ & & & & & & \\
\hline $\begin{array}{l}\text { Maravas \& Pantouvakis } \\
(2012)\end{array}$ & & $\mathbf{X}$ & $\mathbf{X}$ & & & & & & & & \\
\hline Petit (2012) & $\mathbf{X}$ & & & & & & & & & & \\
\hline Klastorin \& Mitchell (2013) & & & & & & & & & $\mathbf{X}$ & & \\
\hline Ranjbar \& Davari (2013) & & & & & & & & & & & $\mathbf{X}$ \\
\hline Acabes et al. (2014) & & & & & & & & $\mathbf{X}$ & & & \\
\hline Dixit et al. (2014) & & & & & & & $\mathbf{X}$ & & & & \\
\hline Zhang \&Elmaghraby (2014) & & $\mathbf{X}$ & $\mathbf{X}$ & & & & & & & & \\
\hline Creemers et al. (2015) & & $\mathbf{X}$ & & & & & & & & & $\mathbf{X}$ \\
\hline Fu et al. (2015) & & $\mathbf{X}$ & & & & $\mathbf{X}$ & & & & & \\
\hline Jeang (2015) & & $\mathbf{X}$ & $\mathbf{X}$ & & & & & & & & \\
\hline Gutjahr (2015) & & $\mathbf{X}$ & $\mathbf{X}$ & & & & & & & & \\
\hline Hazir et al. (2016) & & $\mathbf{X}$ & & & & $\mathbf{X}$ & & & & & \\
\hline Xu et al. (2016) & & & & & & & $\mathbf{X}$ & & & & \\
\hline Liu et al. (2017) & & & & & & & $\mathbf{X}$ & & & & \\
\hline Vaagen et al. (2017) & & & & $\mathbf{X}$ & & & & & & & \\
\hline Bordley et al. (2019) & & & & $\mathbf{X}$ & & & & & & & \\
\hline
\end{tabular}

Bordley et al. (2019)

*Studies that address only variability in activity durations are not included. 


\section{APPROACHES TO MANAGE PROJECT UNCERTAINTY}

To minimize the effect of unexpected events on project performance, five fundamental scheduling approaches have been discussed in published literature: stochastic scheduling, fuzzy scheduling, sensitivity analysis, reactive scheduling and robust (proactive) scheduling (Herroelen and Leus, 2005). This classification is depicted in Figure 2. Details of each approach and implementations with project management will be given in the following sections. We also refer to the handbooks on project scheduling (Demeulemeester and Herroelen, 2002, and Schwindt and Zimmermann, 2015) for methodological analysis.

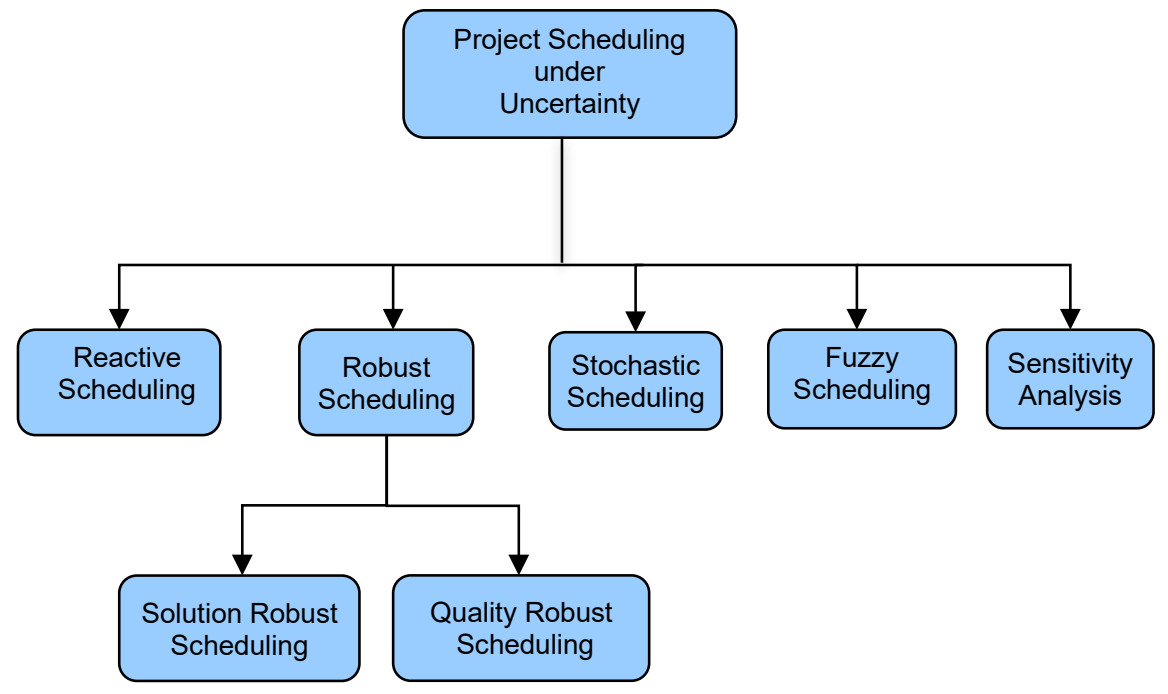

Figure 2. Taxonomy Based on Herroelen and Leus (2005)

\subsection{Reactive Project Scheduling}

Modifying or re-optimizing a schedule in the face of disruptions is called reactive scheduling. If a baseline schedule is prepared before execution, this approach is known as predictive-reactive scheduling. On the other hand, the schedule could be dynamically constructed, and this approach is called dynamic scheduling. The term "rescheduling" is also widely used in published literature. It is sometimes even used as a synonym for "reactive scheduling" (Aytug et al., 2005).

When and how to reschedule are the major questions in reactive scheduling. For timing, two approaches exist. In event-driven scheduling, rescheduling is performed when an unexpected event is observed; whereas in a periodic policy, rescheduling is performed at the beginning of each period. Corrective action in the case of disruptions may be taken as either full or partial rescheduling. In full rescheduling, all the available tasks are rescheduled, whereas in partial scheduling only a part of the current schedule is updated. For further discussion on 
these approaches and applications, the readers are referred to Sabuncuoğlu and Goren (2009) for machine scheduling and to Herroelen and Leus (2004) for project scheduling. Even though there are a large number of reactive machine scheduling applications in published literature, reactive scheduling applications for projects are scarce.

Simulation is a commonly used technique in reactive project scheduling. Yang (1996) conducted a simulation study to show the impacts of rescheduling on project makespan. $\mathrm{He}$ found that a simulated annealing heuristic was more effective in generating the schedules compared to simple dispatching rules. He also demonstrated that the frequency of rescheduling considerably affects the project completion time and that the effect of rescheduling depends on the tightness of precedence and resource constraints. If they are very loose or very tight, the gain achieved through rescheduling is minimal. Using simulation, Van de Vonder et al. (2007b) assessed predictive-reactive resource constrained project scheduling procedures. Schedule stability and timely project completion probability were both considered as performance criterion. In another study, Van de Vonder et al. (2007a) presented heuristics for repairing resource constrained project baseline schedules and used simulation to compare the performances.

Zhu et al. (2005) formulated an integer linear program to recover from project disruptions. They considered disruptions in activity durations, in the network and in resource availabilities, and then modeled the recovery options. In addition to rescheduling, they allowed activity mode changes and allowed increases in the resource availabilities. They optimized a composite objective function, which is a function of the project makespan, schedule stability and recovery cost, and decided among the following recovery options: changing the finish times or modes of the activities, and increasing the resource availabilities.

Deblaere et al. (2011a) addressed multi-mode resource constrained project scheduling and modeled both resource and activity duration disruptions. They developed precise reactive scheduling procedures and a tabu search heuristic for repairing a disrupted schedule. The tabu search heuristic was found to be effective in finding solutions to minimize the rescheduling costs. Their rescheduling procedures followed a "railroad scheduling policy", i.e., no activity can be started before its baseline start time.

\subsection{Robust Project Scheduling}

In proactive or robust scheduling, variability is incorporated into the models, and schedules that are less vulnerable to disruptions are sought. Herroelen and Leus (2005) divided 
schedule robustness into two groups: solution robustness (stability) and quality robustness. In this paper, we use this classification. The solution robustness is defined as the insensitivity of the activity start times with respect to variations in the input data. On the other hand, quality robustness is defined as insensitive to schedule performance, such as project makespan, with respect to disruptions. Quality robust scheduling aims to construct schedules in such a way that the value of the performance measure is affected as little as possible by disruptions.

The most popular approach of project management aiming for quality robustness is critical chain project management (CCPM), introduced by Goldratt (1997) who applied the theory of constraints (TOC) to project management. CCPM stresses the identification and control of system constraints so as to improve the performance of the overall system. Buffers are employed as protection mechanisms against uncertainty and are controlled to monitor project performance. Safety factors are eliminated from individual activities and aggregated at the end as a project buffer. This allows risk pooling; delays in one activity can be compensated by the safety factor removal from another activity. Herroelen and Leus (2001) used simulation to show the weaknesses and strengths of CCPM and test the effect of the scheduling mechanism on makespan.

Inspired by the newsvendor problem, Trietsch (2006) developed an optimization model with linear costs for early and late delivery in determining the size of the feeding buffers. To improve the CCPM buffer management system, Peng and Huang (2014) formulated an optimization model; Hu et al. (2016) integrated activity sensitivity information. Zhang et al. (2016) adjusted the project buffers by analyzing the resource constraints and level of resource association between the activities. By contrast, Zhang et al. (2018) considered the different phases of the projects and allocated a project buffer to each phase, and controlled the buffer dynamically.

Herroelen and Leus (2003) formulated mathematical programming models to construct stable (solution robust) project schedules. They developed a linear programming (LP) model and some benchmark heuristics. Their LP model allowed a single activity disruption, where the duration of one activity increased during the schedule execution. Leus and Herroelen (2004) adapted the stability model to the resource constrained networks using resource flow networks. These networks model the number of resource units transferred between the activities as a flow of resources among activities. In their model, only a single resource type was considered and the branch-and-bound method was used to solve the problem. Van de Vonder et al. $(2005,2006)$ analyzed the trade-off between quality robustness and solution 
robustness. They used a scheduling mechanism that was adapted from the float factor model of Tavares (1998). This model shifts activity start times from their earliest start times in the same proportion as the slack values for all the activities. Van de Vonder et al. (2005) relaxed the resource constraints and concentrated on stability. Van de Vonder et al. (2006) extended the activity dependent float factor model to the resource-constrained environment. In these studies, the quality robustness was measured by the probability that the project will end by the project due date. Lambrechts et al. (2008a) and Van de Vonder et al. (2008) proposed heuristics for solution robust scheduling and compared the performances of the proposed heuristics using simulation. Al Fawzan and Haouari (2005) developed a dual-objective model for the RCPSP and optimized the solution robustness and makespan. Li and Demeulemeester (2016) modeled the robust resource leveling problem by considering solution robustness.

To develop efficient scheduling algorithms, researchers have also worked on developing substitute measures that provide a good estimate of robustness. Chtourou and Haouari (2008), and Khemakhem and Chtourou (2013) developed predictive indicators for resourceconstrained networks. Lamas and Demeulemeester (2016) proposed using the joint probability that each activity starts exactly at its baseline starting time as a measure of robustness. Lambrechts et al. (2011) took resource breakdowns into account and proposed three substitute measures that used uncertainty information. Hazir et al. (2010) focused on the discrete time/cost trade-off problem (DTCTP) and presented a simulation study to test the robustness measures at different uncertainty settings.

In addition to developing heuristic buffer insertion mechanisms, and focusing on scheduling algorithms, robust optimization has been used to develop project plans for more than a decade. It is a well-known mathematical programming technique with many application areas that aims to build solutions that are insensitive to parameter uncertainty (Gabrel et al., 2014). Yamashita et al. (2007) formulated scenarios for uncertain durations and modeled the robust resource availability cost problem. Cohen et al. (2007) and Hazir et al. (2011) assumed interval uncertainty and respectively studied the continuous and discrete time-cost trade-off problem. Bruni et al. (2018) made use of Bertsimas and Sim's (2003) modeling approach - like Hazir et al. (2011) - and allowed only a given number of activities to reach their worst-case parameters simultaneously but in different ways, and addressed the RCPSP. Assuming intervals for activity durations, Conde (2009) brought a minimax regret approach to the critical path problem. To formulate the robust RCPSP, Artigues et al. (2012) used regret-based objectives, Chakrabortty et al. (2017) examined different forms of uncertainty 
sets for activity duration, and Bruni et al. (2017) adopted an adjustable approach where resource allocation is first made and then the starting times are adjusted.

More and more studies focused on combining robust planning and reactive procedures. We refer the readers to Lambrechts et al. (2008b) for a proactive-reactive scheduling application. Instead of developing the proactive plans and reactive procedures separately and then combining them, Davari and Demeulemeester (2017) proposed total integration. They formulated an integrated problem with a combined cost function, which included the cost of baseline schedule and cost of reacting. As a continuation of this study, Davari and Demeulemeester (2018a) investigated the reaction policies in depth: selection-based reactions and buffer-based reactions, and found that buffer-based ones are much more effective. Bendotti et al. (2017) recently addressed the development of reactive and proactive solutions to the CPM-scheduling problem by maximizing the so-called anchorage level, which is the number of equally valued decisions in the solutions of the baseline and real instances. Zheng et al. (2018) worked on the resource constrained scheduling problem with NPV maximization criterion and uncertain durations. To ensure robustness they added time buffers in the baseline schedule, and in addition, integrated two reactive scheduling models into their algorithm.

\subsection{Stochastic Project Scheduling}

The stochastic resource constrained project scheduling problem (SRCPSP) is the stochastic extension of RCPSP. In SRCPSP, activity durations are modeled as random variables with known probability distributions or with some other known information on activity durations. Typically, no baseline schedule is created. The objective is usually the minimization of the expected makespan. For other objectives, the reader can refer to Rostami et al. (2018).

For solving SRCPSP, Stork (2001) proposed exact branch-and-bound algorithms. Another exact algorithm using the Markov chain method was suggested by Creemers (2015). Both of these exact approaches can solve small problems of 30 and 60 activities created by a ProGen instance generator (Kolisch and Sprecher, 1996). Rostami et al. (2018) recently presented a new class of policies and generalized some of the existing classes in published literature. Chen et al. (2018) examined the performance of 17 resource-based priority rule heuristics on SRCPSP, where 15 of these rules were already being applied to RCPSP and the remaining 5 rules were suggested by the authors. They employed the justification technique to further improve the solutions obtained (Valls et al., 2005). They reported that latest finish time (LFT) and statistical latest finish time (SLFT) performed best for solving the SRCPSP. They compared their results with the metaheuristics and concluded that, despite their simplicity, 
the best priority rules can compete with state-of-the-art heuristics. LFT and SLFT work as well as the best existing metaheuristics for large size instances and medium variance, and LFT and SLFT outperform all other metaheuristics proposed so far when the variance is high. Deblaere et al. (2011b) addressed the SRCPSP by following a proactive approach. In addition to a project execution policy, a vector of predictive activity starting times was determined.

Golenko-Ginzburg and Gonik (1997) proposed a resource-based priority policy to obtain a feasible solution for the SRCPSP. The various renewable resource types assigned to activities were assumed to be fixed, and hence, have no influence on the random durations of the activities. They tested their algorithm on only one instance with 36 activities and one resource. In a consecutive paper, Golenko-Ginzburg and Gonik (1998) removed the above restriction and let the amount of renewable resources assigned to an activity be a variable. This way the density function of the activity duration also becomes a function of the resources allocated to that activity. For simplification, they replaced the actual problem to be solved at each decision point by the knapsack resource reallocation problem, which has been shown to be NP-complete. They proposed a lookover algorithm for an exact solution and a heuristic one for relatively larger problems.

Tsai and Gemmill (1998) suggested a tabu search algorithm with multiple tabu lists, randomized short-term memory and multiple starting schedules to obtain resource-based priority policies. They compared their tabu search results over the Patterson instance set (Patterson, 1984) modified to introduce the stochastic dimension. Ballestin (2007) proposed three sampling and three genetic procedures and concluded that the underestimation can be huge when the deterministic makespan is used as an estimate of the expected makespan except when the variability is very small. Ballestin and Leus (2009) employed an adapted version of the greedy randomized adaptive search procedure (GRASP) to generate solutions for SRCPSP, which are shown to outperform other heuristic algorithms in published literature. They compared the expected makespan versus other objectives: service level, makespan variance and expected tardiness. As a result of computational experiments they concluded that for most practical purposes, focusing only on expected makespan would suffice. Bruni et al. $(2011,2015)$ proposed building a baseline schedule that was protected against possible disruptions, and hence, partially bridging the gap between the stochastic and robust scheduling research. They realized this through decoupling the problem by treating the dynamic and stochastic aspects separately and by imposing joint chance constraints at each decision point. 
Fang et al. (2015) proposed an estimation of distribution algorithm (EDA) employing a class of resource-based scheduling policies to solve the SRCPSP. Being an evolutionary metaheuristic, the EDA adopts an activity list representation to encode individuals and use as the fitness value for an activity list $\pi$, where the expected makespan is defined as the average makespan of a predefined number of scenarios of $\pi$. Offspring sampling is based on a probability matrix, and a local search procedure is applied to improve the solutions. The probability matrix is updated using a population-based updating mechanism. The initial population is obtained using regret-based biased random sampling using the LFT priority rule. They reported that the proposed procedure is quite competitive compared to state-ofthe-art heuristics for the SRCPSP and yields the best performance if the variance of the activity duration is medium to large.

Scheduling policies (or scheduling strategies) dynamically make scheduling decisions at decision points corresponding to the start time of activities, and since the activity durations are random variables, these policies do not result in a deterministic schedule but rather in different schedules (Möhring et al., 1984, Demeulemeester and Herroelen, 2006). Chen et al. (2018) referred to static and dynamic scheduling policies and elaborated on different subclasses of static scheduling policies.

Gutjahr et al. (2000) proposed a heuristic version of the stochastic branch-and-bound (B\&B) algorithm combined with Monte Carlo simulation to solve the stochastic discrete time/cost trade-off problem (DTCTP). The expected total cost is the sum of the tardiness and problem costs, which they minimized by choosing from a discrete set of measures with a static assignment to activities. Mitchell and Klastorin (2007) minimized the expected total cost, defined as the sum of the direct, indirect and incentive costs. For that purpose, they developed a heuristic algorithm applicable to any general distribution of activity durations. They also showed that the deterministic approximation approaches, such as Program Evaluation and Review Technique (PERT), produce biased results. Zhu et al. (2007) addressed the project scheduling problem of setting target finish times under uncertain activity durations and a crashing budget constraint. The uncertainty is represented by discrete scenarios. They employed two-stage integer linear stochastic programming, where target times are determined in the first stage and a detailed project schedule in the second stage. The overall objective is to balance the cost associated with the target times and the expected cost of deviating from these target times. Kang and Choi (2015) presented an adaptive approach for the crashing problem, reducing activity durations with some additional cost where each activity can have a due date. Klerides and Hadjiconstantinou (2010) employed decomposition-based stochastic programming to model the stochastic time/cost trade-off 
problem (STCTP). They considered the minimization of project duration subject to a specified budget, and the minimization of the total cost subject to a completion deadline. Godinho and Branco (2012) constructed an adaptive model for multi-mode scheduling under uncertainty. The total cost function consisted of the project cost and tardiness cost. Scheduling policies are defined based on a set of thresholds obtained through a search, and then evaluated it with a Monte Carlo simulation. Starting times of the activities are compared with this set of thresholds so as to define the processing mode.

Assuming stochastic durations, Shen et al. (2010) modeled a resource investment decision model, which integrated the trade-off between the costs of risk for hedge investments with the expected penalties of surpassing the project deadline. They formulated a two stage stochastic programming model and a chance-constrained optimization model, which considers the probability of meeting the constraints and integrates confidence levels for the constraints, individually or jointly. Yang (2005) transformed the stochastic budget constraint into a deterministic equivalent by using chance-constrained programming. Recently, Wang and Ning (2018) presented three uncertain chance-constrained programming models for scheduling projects, and Davari and Demeulemeester (2018b) developed an efficient branchand-bound algorithm for the chance-constrained RCPSP.

Gonik (1999) minimized the expected total storage and penalty costs of renewable resources for random activity durations in the presence of a due date when the resources are prepared and delivered at planned time points such that an activity cannot start earlier than the delivery of the required resources. Thus, there is a penalty cost for late delivery and a storage cost for early delivery. The decision variables were then the delivery times of the resources required. He proposed a coordinate descent method around the delivery times with simulation runs embedded into its search process. Golenko-Ginzburg et al. (2000) dealt with a multi-project decision environment with random activity durations. A due date and a minimum probability of meeting this due date were associated with each project. A fixed amount of each type of resource to be used by all projects was provided. They employed a coordinate descent method where the coordinates referred to the starting times of the projects and the fixed amounts of resources, and they performed the search process using simulation.

Golenko-Ginzburg et al. (2001) addressed a similar problem, but this time they distinguished between two types of resources. Type A resources are rare and expensive and are brought from outside the project management system for a short time and for a small number of activities. An activity cannot start earlier than the delivery of the required A resources. Type $\mathrm{B}$ resources, on the other hand, are regular renewable resources managed from a central pool 
of resources. It is assumed that each project is realized independently with its own due date and a minimum probability of meeting this due date. The objective is the minimization of the sum of expected non-operational costs for each project consisting of leasing and maintaining $\mathrm{B}$ resources, the cost of idle time for A resources, a fixed amount paid to the customer in case of tardiness, as well as per unit time of tardiness and the cost of project storage for each time unit, if finished early. They proposed a simulation model with two sub-models, one employing coordinate wise cyclic optimization and the other integer programming for the allocation of the B resources.

NPV maximization criterion and uncertainty of activity durations have also been addressed using stochastic approaches. Buss and Rosenblatt (1997) found optimal activity delays with respect to earliest start times. Creemers (2018a) recently studied the times and distribution of the NPV. To determine the optimal scheduling policies, Creemers et al. (2010) used stochastic DP based on the continuous-time Markov chain described by Kulkarni and Adlakha (1986). In a more recent study, Creemers (2018b) improved the computational performance. Hermans and Leus (2018) investigated the case where preemption of resources was allowed and showed the optimal case for a non-preemptive policy.

\subsection{Fuzzy Project Scheduling}

Fuzzy programming has attracted the attention of many researchers as an alternative paradigm to address project scheduling problems with uncertainty, motivated by the pioneering work of Bellman and Zadeh (1970). Instead of using random variables, uncertain parameters are modeled as fuzzy numbers and the constraints are defined with the use of fuzzy sets and membership functions. Membership functions might allow some constraint violations and measure the degree of satisfaction of the constraints. The advocates of the fuzzy activity duration approach claim that probability distributions for the activity durations are usually unknown due to reasons like the lack of accurate historical data. They also claim that activity durations estimated by human experts are potentially inaccurate. For details of the theory and applications of fuzzy programming, we refer to Zimmerman (2001).

Studies on fuzzy project scheduling have substantially increased in the last 15 years. Hence, only a certain number of them are reviewed below.

Hapke and Slowinski $(1994,1996)$ generated a set of schedules applying twelve dispatch rules and selected the schedule with the least fuzzy makespan. Wang (2002, 2004) concentrated on product development projects and used fuzzy set theory to generate robust 
schedules. Özdamar and Alanya (2001) addressed software development projects using fuzzy functions to model uncertainty in the durations of activities.

Chen and Tsai (2011) combined the time-cost trade-off problem into one with fuzzy parameters and formulated a linear program (LP) with fuzzy coefficients. LP was also used by Zareei et al. (2011) to calculate the earliest and latest event times in fuzzy project scheduling problems. Çebi and Otay (2015) optimized multiple criteria by making use of fuzzy multi-objective linear programming. They employed project completion time, total project cost, the earliest time of an important event and any event to which management pays special attention, as the multiple criteria. Xu et al. (2012) and Tavana et al. (2014) also addressed multi-objective decision making, and focused on the trade-offs in project time planning. To model conflicting goals, Liang (2010) employed fuzzy goal programming. Gang et al. (2013) solved the multi-mode, multi-project resource allocation problem (MRAMPSP) under fuzzy random environments with a dual-level approach under stochastic activity durations and costs - defined as the sum of the resource costs and the total tardiness penalty for the multiple projects. The decision maker at the upper level, the company manager, seeks to allocate the company resources to multiple projects at the lowest total cost, where the costs are defined as above. At the lower level, each project manager tries to schedule the allocated resources in such a way as to minimize the duration of the project they manage.

\subsection{Sensitivity Analysis}

Sensitivity analysis has been widely used in mathematical modeling. We refer to Borgonovo and Plischke (2016) for a review of available methods and recent developments, and to Hall and Posner (2004) for relevant examples. We stress that applications of sensitivity analysis to project scheduling problems are very limited in published literature.

Gálvez and Capuz-Rizo (2016) applied different sensitivity analysis techniques to find out the parameters that had the largest effect. Hajdu and Bokor (2016) examined the impact of probability distributions for activity durations on project completion time and concluded that the accuracy of the three-point estimation is significantly more important than the type of the probability distribution.

We summarized the classification results for literature based on uncertainty management approaches in Table 2. We noted that there are more robust scheduling studies than the reactive scheduling applications. Interestingly, we found only one paper published in reactive scheduling between 2009 and 2016. However, the researchers seem to have 
refocused their attention on the reactive approach, especially on its combination with a robust approach, in the last three years. Stochastic project scheduling is not included in the table since it has been studied for a long time and there is a vast amount of literature on it.

\subsection{A Critical Analysis of the Approaches}

During project execution, various problem characteristics, such as resource availability or processing times, may change due to disruptions like machine breakdowns. These changes generate additional information. Therefore, reactive scheduling also allows the process to take into consideration new information encountered during the execution of the project, and scheduling with new information naturally improves the project performance. At this point, some immediate questions arise: When to reschedule? How to reschedule? What is the effect of rescheduling on stability?

There are three alternatives possible in response to the question of when to schedule: periodic scheduling, continuous scheduling and adaptive scheduling. In periodic scheduling, the schedule is revised periodically, whereas in continuous scheduling, the schedule is revised after a number of events occur that change the system state. In adaptive scheduling, on the other hand, scheduling is performed when a predetermined amount of deviation from the original schedule is observed. It is also possible to combine these approaches and develop hybrid methods. When-to-schedule policies have been investigated in many machine scheduling studies (Sabuncuoglu and Goren, 2009). In project scheduling, policies need to be developed together with a thorough analysis of the advantages and disadvantages of these policies.

In how-to-schedule decisions, full and partial rescheduling are the alternatives. All the available tasks are re-planned in full rescheduling, whereas in partial rescheduling only a part of the current schedule is updated. Full rescheduling is better in terms of project performance. On the other hand it requires more computational effort than partial scheduling. Partial rescheduling is preferable when stability is considered. In order to decide which method to use, the performance differences of these methods should be calculated. As rescheduling frequency increases, the system responsiveness increases. On the other hand, rescheduling too often increases system instability. A compromise between stability and project performance should be aimed for in the rescheduling research.

Combining reactive and robust project scheduling improves project performance. This combined approach is relatively new in scheduling literature and referred to as "proactivereactive scheduling". As shown by Lambrechts et al. (2008b) proactive-reactive scheduling 
protects against disruptions through the combination of a proactive scheduling procedure and a reactive improvement procedure.

Stochastic programming uses probabilistic models to describe uncertain data in terms of probability distributions. Typically, the average performance of the system is examined and an assumption for the expected probability distribution is taken. Stochastic programming models are usually computationally demanding, but when accurate distributional information is available, stochastic programming has the advantage of incorporating this available distribution information. If the decision maker either does not have, or cannot access this information, other approaches are more appropriate. As projects are temporary and unique, and have a finite duration and distinguishing characteristics, managers cannot have access to probability information in many real-life projects.

The major advantage of robust approaches over stochastic programming is that no assumptions about the uncertainty of data are required regarding the underlying probability distribution. On the other hand, as worst-case conditions are emphasized in robust optimization, in some cases the expected performance of the generated solutions might be worse when compared to the solutions generated using stochastic programming.

Sensitivity analysis investigates the dependence of the model output on its input parameters. Generally the effect of small perturbations on the optimal solution is analyzed. Sensitivity analysis is distinctively different from stochastic programming, robust optimization and fuzzy modeling, since it analyzes the impacts of parameter changes on the performance of the selected solutions, but it does not address uncertainty in the modeling phase.

\section{CONCLUSIONS AND FUTURE RESEARCH DIRECTIONS}

In this study, we investigated and comprehensively discussed the models and algorithms for project modeling under conditions of uncertainty. The main contribution of this paper is the presentation of a classification scheme based on the sources of uncertainty in project management, and reviewing the current studies modeling these sources. A further contribution is the extensive investigation of the techniques and approaches to manage uncertainty. Finally we underline the research gaps and discuss the future research perspectives.

Regarding the methods, stochastic scheduling has been widely studied in project management for decades. Reactive, robust and fuzzy scheduling have all increased in 
popularity among researchers during the last 20 years. In addition to the buffer insertion and reactive policy design studies, applications of different robust optimization methods have recently attracted the attention of researchers. The applications of fuzzy methods have also rapidly increased.

An important role of this survey was to highlight the research areas that are worth further investigation, and emphasize their practical needs. We have summarized some possible directions for future work as follows:

- The fact that the relatively excessive amount of work put into managing uncertainty in activity durations compared to those related to other sources of uncertainty indicates the need for further research in those other areas. Uncertainty in activity durations is a result of various sources and uncertainty is considered only implicitly through the management approaches. Hence, research into reducing the impact of the individual sources of uncertainty would be crucial in improving the effectiveness of project planning.

- The studies addressing the uncertainty due to other sources, especially the organizational and external factors such as the environment or market related ones are scarce (see Table 1). Regarding the uncertainty in resources, randomness in availabilities has been investigated relatively more than the requirements.

- Existing studies generally investigate either a single source of uncertainty or study a source such as resource availabilities with random activity durations. Research investigating multiple sources, their relationships and developing models to deal with combined sources are promising. To give an example: in many large-scale infrastructure projects, timing of cash payments is uncertain as well as the durations and resource usages. Moreover, uncertainty in financial markets and their impact on the discount rates should not be neglected. However, as RCPSPs are already NP-hard (Blaziewicz et al., 1983), integrating all these uncertain factors would make the problems even more difficult to solve. Developing efficient solution algorithms to solve real-life examples would indeed be a challenge.

- In real-life projects, usually multiple alternatives exist to execute resource-use activity. Multi-mode scheduling problems have practical implications, as they model the time/cost or time/resource relationships in processing activities. In the domain of project scheduling, few studies address multi-mode scheduling under conditions of uncertainty. This research field is still quite open. See Hazir et al. (2015) for a discussion on different robust optimization approaches and the potential application areas in multi-mode scheduling problems.

- Although quality is cited among the triple performance measures for project managers, together with project duration and cost, there are only a few studies explicitly addressing quality, let alone handling uncertainty, in quality assurance. 
- Protection of the environment and efficient use of natural resources have become crucial elements in project planning. Studies addressing environmental objectives and uncertainty are also scarce. Time, cost, quality and sustainability have all become critical dimensions of project performance. In that sense, optimization models that address multiple criteria as well as integrating uncertainty are better adapted to the requirements of industry. There is a need for further studies on multiple criteria methods.

- When we examine the methods, the literature on reactive scheduling has mainly considered the machine environments. There is a need for further studies in reactive project scheduling, especially with algorithms, to determine when to react and how to react in an uncertain environment so as to minimize the effect of disruptions on project performance. Proactive and reactive planning are complementary aspects of scheduling. Models combining robust scheduling and reactive scheduling are quite recent. This combined approach is valuable as the baseline schedule might be created by the maximization of a robustness measure, and a reactive policy might be integrated into the algorithm. By developing such predictive-reactive approaches, managers could benefit both from the anticipation and stability of the proactive approach and the responsiveness of the reactive approaches. A problem of interest for project managers would be where the robustness cost and the adjustment cost of the baseline schedule are to be balanced through the integration of proactive and reactive scheduling.

- In addition to scheduling, design of project control systems is crucial to minimize the deviations from the project plan during the execution phase. Scheduling/rescheduling and monitoring and control tools have usually been studied separately. However, integration of these functions can facilitate information sharing, coordination and effective resource allocation. Control policies need to be set when considering the schedules and objectives, and control data is valuable to make rescheduling decisions. Despite its importance, this relationship has not been studied theoretically in sufficient depth. How to combine the scheduling algorithms with monitoring and control procedures that define effective intervening strategies in case of disruptions is an open research question (see Hazir and Schmidt (2013) for an example of an integrated model).

- The practical impact of the models and algorithms that we discussed could be realized by developing integrated DSSs. They are essential elements of the DSS and comprise the modeling and optimization modules of an integrated DSS. These DSSs counsel project managers to generate protected schedules that help to proactively minimize the deviations from the project objectives. DSSs, which guide the managers in determining the possible need for corrective actions, such as rescheduling during execution, are also required. They need to include optimization models that work to determine the timing and magnitude of corrective actions. Therefore, OR tools, which have been widely applied to modeling and 
solving project scheduling problems, could also be embedded in the modeling bases of DSSs. Integrating the DSS into widely used commercial software packages would be very valuable in practice, as it enhances the scheduling functions of these packages. 
Table 2. Literature Analysis based on Uncertainty Management Approaches*

\begin{tabular}{|c|c|c|c|c|c|}
\hline \multirow{2}{*}{$\begin{array}{c}\text { Author(s) } \\
\text { (Ordered wrt. Publication Year) }\end{array}$} & \multirow{2}{*}{$\begin{array}{c}\text { Reactive } \\
\text { Scheduling }\end{array}$} & \multicolumn{2}{|c|}{ Robust Scheduling } & \multirow{2}{*}{$\begin{array}{c}\text { Fuzzy } \\
\text { Scheduling }\end{array}$} & \multirow{2}{*}{$\begin{array}{l}\text { Sensitivity } \\
\text { Analysis }\end{array}$} \\
\hline & & Stability & Quality Robustness & & \\
\hline Hapke and Slowinski $(1994,1996)$ & & & & $\mathrm{x}$ & \\
\hline Yang (1996) & $\mathrm{x}$ & & & & \\
\hline Tavares (1998) & & & $\mathrm{x}$ & & \\
\hline Herroelen and Leus (2001) & & & $\mathrm{x}$ & & \\
\hline Ozdamar and Alanya (2001) & & & & $\mathrm{x}$ & \\
\hline Wang $(2002,2004)$ & & & & $\mathrm{x}$ & \\
\hline Herroelen and Leus (2003) & & $\mathrm{x}$ & & & \\
\hline Leus and Herroelen (2004) & & $\mathrm{x}$ & & & \\
\hline Al-Fawzan and Haouari (2005) & & $\mathrm{x}$ & & & \\
\hline Zhu et al. (2005) & $\mathrm{x}$ & & & & \\
\hline Van de Vonder et al. $(2005,2006)$ & $\mathrm{x}$ & $\mathrm{x}$ & & & \\
\hline Tukel et al. (2006) & & & $\mathrm{x}$ & & \\
\hline Trietsch (2006) & & & $\mathrm{x}$ & & \\
\hline Cohen et al. (2007) & & & $\mathrm{x}$ & & \\
\hline Van de Vonder et al. (2007a) & $\mathrm{X}$ & & & & \\
\hline Van de Vonder et al. (2007b) & $\mathrm{x}$ & $\mathrm{x}$ & & & \\
\hline Yamashita et al. (2007) & & & $\mathrm{x}$ & & \\
\hline Chtourou and Haouari. (2008). & & & $\mathrm{x}$ & & \\
\hline Lambrechts et al. (2008a) & $\mathrm{X}$ & & & & \\
\hline Lambrechts et al. (2008b) & $\mathrm{x}$ & $\mathrm{x}$ & & & \\
\hline Van de Vonder et al. (2008) & & $\mathrm{x}$ & & & \\
\hline Conde (2009) & & & $\mathrm{x}$ & & \\
\hline Hazir et al. $(2010,2011)$ & & & $\mathrm{x}$ & & \\
\hline Liang (2010) & & & & $\mathrm{x}$ & \\
\hline Chen and Tsai (2011) & & & & $\mathrm{x}$ & \\
\hline Deblaere et al. (2011a) & $\mathrm{x}$ & & & & \\
\hline Lambrechts et al. (2011) & & $\mathrm{x}$ & & & \\
\hline
\end{tabular}

* Stochastic project scheduling is not included 
Table 2. Literature Analysis based on Uncertainty Management Approaches (Continued) *

\begin{tabular}{|c|c|c|c|c|c|}
\hline \multirow{2}{*}{$\begin{array}{l}\text { Author(s) } \\
\text { (Ordered wrt. Publication Year) }\end{array}$} & \multirow{2}{*}{$\begin{array}{l}\text { Reactive } \\
\text { Scheduling }\end{array}$} & \multicolumn{2}{|c|}{ Robust Scheduling } & \multirow{2}{*}{$\begin{array}{c}\text { Fuzzy } \\
\text { Scheduling }\end{array}$} & \multirow{2}{*}{$\begin{array}{c}\text { Sensitivity } \\
\text { Analysis }\end{array}$} \\
\hline & & Stability & Quality Robustness & & \\
\hline $\mathrm{Xu}$ et al. (2012) & & & & $\mathrm{x}$ & \\
\hline Zareei et al. (2011) & & & & $\mathrm{x}$ & \\
\hline Gang et al. (2013) & & & & $\mathrm{x}$ & \\
\hline Khemakhem and Chtourou (2013). & & & $\mathrm{x}$ & & \\
\hline Tavana et al. (2014) & & & & $\mathrm{x}$ & \\
\hline Peng and Huang (2014) & & & $\mathrm{x}$ & & \\
\hline Cebi and Otay (2015) & & & & $\mathrm{x}$ & \\
\hline Gálvez and Capuz-Rizo (2016) & & & & & $\mathrm{x}$ \\
\hline Hajdu and Bokor (2016) & & & & & $\mathrm{x}$ \\
\hline Hu et al. (2016) & & & $\mathrm{x}$ & & \\
\hline Li and Demeulemester (2016) & & $\mathrm{x}$ & & & \\
\hline Zhang et al. $(2016,2018)$ & & & $\mathrm{x}$ & & \\
\hline Bruni et al. $(2017,2018)$ & & & $\mathrm{x}$ & & \\
\hline Bendotti et al. (2017) & $\mathrm{x}$ & & $\mathrm{x}$ & & \\
\hline Chakrabortty et al. (2017) & & & $\mathrm{x}$ & & \\
\hline Davari and Demeulemester $(2017,2018 \mathrm{a})$ & $\mathrm{x}$ & $\mathrm{x}$ & $\mathrm{x}$ & & \\
\hline Zheng et al. (2018) & $\mathrm{x}$ & & $\mathrm{x}$ & & \\
\hline
\end{tabular}

* Stochastic project scheduling is not included 


\section{References:}

Acebes, F., Pajares, J., Galán, J.M. \& López-Paredes, A. (2014). Exploring the influence of seasonal uncertainty in project risk management. Procedia-Social and Behavioral Sciences, 119, 329-338.

Al-Fawzan, M.A., \&, Haouari, M. (2005), A bi-objective model for robust resource-constrained project scheduling, International Journal of Production Economics, 96, 175-187.

Al-Tabtabai, H., \& Alex, A.P. (2000). Modeling the cost of political risk in international construction projects. Project Management Journal, 31(3), 4-13.

Artigues, C, \& Roubellat, F. (2000). A polynomial activity insertion algorithm in a multi-resource schedule with cumulative constraints and multiple modes. European Journal of Operational Research, 127(2), 297-316.

Artigues, C, Michelon, P. \& Reusser, S. (2003). Insertion techniques for static and dynamic resource constrained project scheduling. European Journal of Operational Research, 149(2), 249-267.

Artigues, C., Leus, R., \& Nobibon, F.T. (2013). Robust optimization for resource-constrained project scheduling with uncertain activity durations. Flexible Services and Manufacturing Journal, 25(1-2), 175-205.

Ashtiani, B., Leus, R., \& Aryanezhad, M.B. (2011). New competitive results for the stochastic resource-constrained project scheduling problem: exploring the benefits of pre-processing. Journal of Scheduling, 14, 157-171.

Atkinson, R., Crawford, L., \& Ward, S., (2006). Fundamental uncertainties in projects and the scope of project management. International Journal of Project Management, 24(8), 687-698.

Aytug, H., Lawley, M.A., McKay, K., Mohan, S. \& Uzsoy, R. (2005). Executing production schedules in the face of uncertainties: A review and some future directions. European Journal of Operational Research, 161(1), 86-110.

Babu, A. \& Suresh, N. (1996). Project management with time, cost, and quality considerations. Journal of Operational Research, 88, 320-327.

Ballestin, F. (2007). When it is worthwhile to work with the stochastic RCPSP? Journal of Scheduling, 10,153-166. 
Ballestin, F. \& Leus, R. (2009). Resource-constrained project scheduling for timely project completion with stochastic activity durations. Production and Operations Management, 18(4), 459474.

Bellman, R., \& Zadeh L. A. (1970). Decision-making in a fuzzy environment. Management Science, $17,141-161$.

Bendotti, P., Chrétienne, P., Fouilhoux, P. \& Quilliot, A. (2017). Anchored reactive and proactive solutions to the CPM-scheduling problem. European Journal of Operational Research, 261(1), 67-74.

Bertsimas, D., \& Sim, M. (2003). Robust discrete optimization and network flows. Mathematical programming, 98(1-3), 49-71.

Birbil, S.I. \& Fang, S.C. (2003). An electromagnetism-like mechanism for global optimization. Journal of Global Optimization, 25, 263-282.

Bordley, R.F., Keisler, J.M. \& Logan, T.M. (2019). Managing projects with uncertain deadlines, European Journal of Operational Research, 274(1), 291-302

Borgonovo, E. \& Plischke, E. (2016). Sensitivity analysis: A review of recent advances. European Journal of Operational Research, 248, 869-887.

Boute, R., Demeulemeester, E. \& Herroelen, W. (2004). A real options approach to project management. International Journal of Production Research. 42(9), 1715-1725.

Bruni, M.E., Beraldi, P., Guerriero, F. \& Pinto, E. (2011). A heuristic approach for resource constrained project scheduling with uncertain activity durations. Computers \& Operations Research. $38,1305-1318$.

Bruni, M.E., Beraldi, P. \& Guerriero, F. (2015). The stochastic resource-constrained project scheduling problem. In C. Schwindt and J. Zimmermann (eds.), Handbook on Project Management and Scheduling Vol. 2, 811-835, Springer International Publishing, Switzerland.

Bruni, M.E., Di Puglia Pugliese, L., Beraldi, P., \& Guerriero, F., E. (2017). An adjustable robust optimization model for the resource-constrained project scheduling problem with uncertain activity durations. Omega, 71, 66-84.

Bruni, M. E., Pugliese, L. D. P., Beraldi, P., \& Guerriero, F. (2018). A computational study of exact approaches for the adjustable robust resource-constrained project scheduling problem. Computers \& Operations Research, 99, 178-190. 
Buss, A.H. \& Rosenblatt, M.J. (1997). Activity delay in stochastic project networks. Operations Research, 45(1), 126-139.

Çebi, F. \& Otay, I. (2015). A fuzzy multi-objective model for solving project network problem with bonus and incremental penalty cost. Computers \& Industrial Engineering, 82, 143-150.

Chakrabortty, R.K., Sarker, R.A. \& Essam, D.L. (2017). Resource constrained project scheduling with uncertain activity durations. Computers \& Industrial Engineering, 112, 537-550.

Chen, S.P. \&Tsai, M.J. (2011). Time-cost trade-off analysis of project networks in fuzzy environments. European Journal of Operational Research, 212(2), 386-397.

Chen, Z., Demeulemeester, E., Sijun, B., \& Yuntao, G., (2018). Efficient priority rules for the stochastic resource-constrained project scheduling problem. European Journal of Operational Research, 270(3), 957-967.

Chtourou, H. \& Haouari, M. (2008). A two-stage-priority-rule-based algorithm for robust resourceconstrained project scheduling. Computers and Industrial Engineering, 55(1), 183-194.

Cohen, I., Golany B. \& Shtub, A. (2007). The stochastic time/cost trade-off problem: a robust optimization approach. Networks, 49, 175-188.

Conde, E. (2009). A minmax regret approach to the critical path method with task interval times. European Journal of Operational Research, 197(1), 235-242.

Creemers, S. (2015). Minimizing the expected makespan of a project with stochastic activity durations under resource constraints. Journal of Scheduling, 18(3), 263-273.

Creemers, S. (2018a). Moments and distribution of the net present value of a serial project. European Journal of Operational Research, 267(3), 835-848.

Creemers, S. (2018b). Maximizing the expected net present value of a project with phase-type distributed activity durations: an efficient globally optimal solution procedure. European Journal of Operational Research, 267(1), 16-22.

Creemers, S., Leus, R. \& Lambrecht, M. (2010). Scheduling Markovian PERT networks to maximize the net present value. Operations Research Letters, 38(1), 51-56. 
Creemers, S., De Reyck, B. \& Leus, R. (2015). Project planning with alternative technologies in uncertain environments. European Journal of Operational Research, 242(2), 465-476.

Davari, M., \& Demeulemeester, E. (2017). The proactive and reactive resource-constrained project scheduling problem. Journal of Scheduling, 1-27.

Davari, M., \& Demeulemeester, E. (2018a). Important classes of reactions for the proactive and reactive resource-constrained project scheduling problem. Annals of Operations Research, 1-24.

Davari, M., \& Demeulemeester, E. (2018b). A novel branch-and-bound algorithm for the chanceconstrained resource-constrained project scheduling problem. International Journal of Production Research, 1-18.

Deblaere F., Demeulemeester E., Herroelen W., \& Van de Vonder S. (2007). Robust resource allocation decisions in resource-constrained projects. Decision Sciences, 38(1), 5-37.

Deblaere, F., Demeulemeester, E. \& Herroelen, W. (2011a). Reactive scheduling in the multi-mode RCPSP. Computers \& Operations Research, 38(1), 63-74.

Deblaere, F., Demeulemeester, E. \& Herroelen, W. (2011b). Proactive policies for the stochastic resource-constrained project scheduling problem. European Journal of Operational Research, 214(2), 308-316.

Demeulemeester, E.L. \& Herroelen, W.S. (2002). Project Scheduling: A Research Handbook (Vol. 49). Kluwer Academic Publishers, Boston.

De Reyck, B. \& Leus, R. (2008). R\&D-project scheduling when activities may fail. IIE Transactions, 40(4), 367-384.

Dixit, V., Srivastava, R.K. \& Chaudhuri, A. (2014). Procurement scheduling for complex projects with fuzzy activity durations and lead times. Computers \& Industrial Engineering, 76, 401-414.

Elmaghraby, S. E. (2005). On the fallacy of averages in project risk management. European Journal of Operational Research, 165, 307-313.

Engwall, M. \& Jerbrant, A (2003). The resource allocation syndrome: the prime challenge of multiproject management? International Journal of Project Management, 21 (6), 403-409.

Estevez-Fernandez, A. (2012). A game theoretical approach to sharing penalties and rewards in projects. European Journal of Operational Research, 216(3), 647-657. 
Fang, C., Kolisch, R., Wang, L. \& Chundi, M. (2015). An estimation of distribution algorithm and new computational results for the stochastic resource-constrained project scheduling problem. Flexible Services and Manufacturing Journal, 27(4), 585-605.

Fu, N., Lau, H.C. \& Varakantham, P. (2015). Robust execution strategies for project scheduling with unreliable resources and stochastic durations. Journal of Scheduling, 18(6), 607-622.

Gabrel, V., Murat, C. \& Thiele, A., 2014. Recent advances in robust optimization: An overview. European Journal of Operational Research, 235(3), 471-483.

Gang J., Xu J. \& Xu Y. (2013). Multi-project resources allocation model under fuzzy random environment and its application to industrial equipment installation engineering. Journal of Applied Mathematics. http://dx.doi.org/10.1155/2013/818731.

Gálvez, E.D. \& Capuz-Rizo, S.F (2016). Assessment of global sensitivity analysis methods for project scheduling. Computers \& Industrial Engineering, 93,110-120.

Godinho, P. \& Branco, F.G. (2012). Adaptive policies for multi-mode project scheduling under uncertainty. European Journal of Operational Research, 216(3), 553-562.

Goldratt, E.M. \& Cox J. (1984). The Goal. North River Press, Croton-on-Hudson, NY.

Goldratt, E.M. (1997). Critical Chain. Great Barrington: The North River Press Publishing Corporation, MA.

Golenko-Ginzburg, D., \& Gonik A. (1997). Stochastic network project scheduling with nonconsumable limited resources. International Journal of Production Economics, 48, 29-37.

Golenko-Ginzburg, D. and A. Gonik. (1998). A heuristic for network project scheduling with random activity durations depending on the resource allocation. International Journal of Production Economics, 55, 149-162.

Golenko-Ginzburg, D., Gonik, A. \& Sitniakovski, S. (2000). Resource constrained project scheduling for several stochastic network projects. Communications in Dependability and Quality Management, $3(1), 63-73$.

Golenko-Ginzburg, D., Gonik, A. \& Sitnyakovskii, S. (2001). Algorithms of optimal supply of resources to a group of projects. Automation and Remote Control, 62(8), 1366-1375. 
Gonik, A. (1999). Resource scheduling model with cost objectives for stochastic network projects. Communications in Dependability and Quality Management, 2(1), 102-108.

Gutjahr, W.J. (2015). Bi-objective multi-mode project scheduling under risk aversion. European Journal of Operational Research, 246(2), 421-434.

Gutjahr, W.J., Strauss C. \& Wagner E. (2000). A stochastic branch-and-bound approach to activity crashing in project management, INFORMS Journal on Computing, 12(2), 125-135.

Hajdu, M. \& Bokor, O. (2016). Sensitivity analysis in PERT networks: Does activity duration distribution matter? Automation in Construction, 65, 1-8.

Hall, N.G. \& Posner M.E. (2004). Sensitivity analysis for scheduling problems, Journal of Scheduling 7(1), 49-83.

Hapke, M. \& Slowinski R. (1994). Fuzzy project scheduling system for software development, Fuzzy Sets and Systems, 67,101-117.

Hapke, M. \& Slowinski R. (1996). Fuzzy priority heuristics for project scheduling, Fuzzy Sets and Systems. 83, 291-299.

Hazır, Ö., Haouari, M. \& Erel, E., (2010). Robust scheduling and robustness measures for the discrete time/cost trade-off problem. European Journal of Operational Research, 207(2), 633-643.

Hazır, Ö., Erel, E. \& Günalay, Y. (2011). Robust optimization models for the discrete time/cost tradeoff problem. International Journal of Production Economics, 130(1), 87-95.

Hazır, Ö. \& Schmidt, K.W. (2013). An integrated scheduling and control model for multi-mode projects. Flexible Services and Manufacturing Journal, 25(1-2), 230-254.

Hazır, Ö. (2015). A review of analytical models, approaches and decision support tools in project monitoring and control. International Journal of Project Management, 33(4), 808-815.

Hazır, Ö., Haouari, M., \& Erel, E. (2015). Robust optimization for the discrete time-cost tradeoff problem with cost uncertainty. In C. Schwindt and J. Zimmermann (eds.), Handbook on Project Management and Scheduling Vol. 2, 865-874, Springer International Publishing, Switzerland. 
Hazır, Ö., Onur A. Kilic \& Tunc H. (2016, April). A Dynamic Programming Model for Project Scheduling under Financial Risks. $15^{\text {th }}$ International Conference on Project Management and Scheduling (PMS2016), 239-242, Valencia, Spain.

Hermans, B., \& Leus, R. (2018). Scheduling Markovian PERT networks to maximize the net present value: new results. Operations Research Letters, 46(2), 240-244.

Herroelen W. \& R. Leus. (2001).On the merits and pitfalls of critical chain scheduling, Journal of Operations Management, 19, 559-577.

Herroelen W. \& Leus R. (2003). The construction of stable project baseline schedules, European Journal of Operational Research, 156, 550-565.

Herroelen, W. \& Leus, R. (2004). Robust and reactive project scheduling: a review and classification of procedures. International Journal of Production Research, 42(8), 1599-1620.

Herroelen W. \& Leus R. (2005). Project scheduling under uncertainty - survey and research potentials. European Journal of Operational Research, 165, 289-306.

Hu, X., Cui, N., Demeulemeester, E. \& Bie, L. (2016). Incorporation of activity sensitivity measures into buffer management to manage project schedule risk. European Journal of Operational Research, 249(2), 717-727.

Huchzermeier, A. \& Loch, C.H. (2001). Project management under risk: Using the real options approach to evaluate flexibility in R\&D. Management Science, 47(1), 85-101.

Jeang, A. (2015). Project management for uncertainty with multiple objectives optimization of time, cost and reliability. International Journal of Production Research, 53(5), 1503-1526.

Jensen C., Staffan J., \& Löfström M. (2006). Project relationships - A model for analyzing interactional uncertainty. International Journal of Project Management, 24(1), 4-12.

Jørgensen, T., \& Wallace, S.W. (2000). Improving project cost estimation by taking into account managerial flexibility. European Journal of Operational Research, 127 (2), 239-251.

Kang, C. \& Choi, B.C. (2015). An adaptive crashing policy for stochastic time-cost tradeoff problems. Computers \& Operations Research, 63, 1-6. 
Kim, J., Kang, C. \& Hwang, I. (2012). A practical approach to project scheduling: considering the potential quality loss cost in the time-cost tradeoff problem. International Journal of Project Management, 30(2), 264-272.

Klerides E., Hadjiconstantinou E. (2010). A decomposition-based stochastic programming approach for the project scheduling problem under time/cost trade-off settings and uncertain durations. Computers \& Operations Research, 37 (12), 2131-2140.

Khemakhem, M.A. \& Chtourou, H. (2013). Efficient robustness measures for the resource-constrained project scheduling problem. International Journal of Industrial and Systems Engineering, 14(2), 245 267.

Klastorin, T. \& Mitchell, G. (2013). Optimal project planning under the threat of a disruptive event. IIE Transactions, 45(1), 68-80.

Kolisch, R. \& Sprecher, A (1996). PSPLIB - a project scheduling problem library. European Journal of Operational Research, 96, 205-216.

Kulkarni,V.G. \& Adlakha, V.G. (1986). Markov and Markov-regenerative PERT networks. Operations Research, 34(5), 769-781.

Lamas, P. \& Demeulemeester, E. (2016). A purely proactive scheduling procedure for the resourceconstrained project scheduling problem with stochastic activity durations. Journal of Scheduling, 19(4), 409-428.

Lambrechts, O., Demeulemeester, E. \& Herroelen, W. (2008a). A tabu search procedure for developing robust predictive project schedules. International Journal of Production Economics, 111(2), 493-508.

Lambrechts, O., E. Demeulemeester \& W. Herroelen (2008b), Proactive and reactive strategies for resource-constrained project scheduling with uncertain resource availabilities, Journal of Scheduling, 11(2), 121-136.

Lambrechts, O., Demeulemeester, E. \& Herroelen, W., (2011). Time slack-based techniques for robust project scheduling subject to resource uncertainty. Annals of Operations Research, 186(1), 443-464. 
Leifer, R., O'connor, G. C., \& Rice, M. (2001). Implementing radical innovation in mature firms: The role of hubs. Academy of Management Perspectives, 15(3), 102-113.

Leus R. \& Herroelen W. (2004). Stability and resource allocation in project planning, IIE Transactions, 36, 667-682.

Li, H. \& Demeulemeester, E. (2016). A genetic algorithm for the robust resource leveling problem. Journal of Scheduling, 19(1), 43-60.

Liang, T.F. (2010). Applying fuzzy goal programming to project management decisions with multiple goals in uncertain environments. Expert Systems with Applications, 37(12), 8499-8507.

Liu, Q., Xu, J. \& Qin, F. (2017). Optimization for the integrated operations in an uncertain construction supply chain. IEEE Transactions on Engineering Management, 64(3), 400-414.

Meredith J.R. \& Mantel S.J. Jr. (2005). Project Management A Managerial Approach, (6th ed.) New York: John Wiley \& Sons.

Maravas, A., \& Pantouvakis, J. P. (2012). Project cash flow analysis in the presence of uncertainty in activity duration and cost. International journal of Project Management, 30(3), 374-384.

Miller, R., \& Lessard, D. (2001). Understanding and managing risks in large engineering projects. International Journal of Project Management, 19(8), 437-443.

Mitchell, G. \& Klastorin, T. (2007). An effective methodology for the stochastic project compression problem. IIE Transactions, 39(10), 957-969.

Möhring, R., Radermacher, F., \& Weiss, G., (1984). Stochastic scheduling problems I - Set strategies. Zeitschrift für Operations Research, 28, 193-260.

Ning, M., He, Z., Jia, T. \& Wang, N. (2017). Metaheuristics for multi-mode cash flow balanced project scheduling with stochastic duration of activities. Automation in Construction, 81, 224-233.

Nozick, L.K., Turnquist, M. A., \& Xu, N. (2004). Managing portfolios of projects under uncertainty. Annals of Operations Research, 132(1-4), 243-256. 
Ortiz-Pimiento, N.P. \& Diaz-Serna, F.J. (2018), The project scheduling problem with nondeterministic activities duration: A literature review, Journal of Industrial Engineering and Management, 11(1), 116-134.

Özdamar, L. \& Dündar, H. (1997). A flexible heuristic for a multi-mode capital constrained project scheduling problem with probabilistic cash inflows, Computers \& Operations Research, 24(12), 1187 1200.

Özdamar, L. (1998). On scheduling project activities with variable expenditure rates, IIE Transactions, 30, 695-704.

Özdamar L. \& Alanya, E. 2001. Uncertainty modelling in software development projects (with case study). Annals of Operations Research, 102, 157-178.

Padalkar, M. \& Gobinath, S. (2016). Six decades of project management research: Thematic trends and future opportunities. International Journal of Project Management, 34, 1305- 1321.

Patterson, J.H. (1984). A comparison of exact procedures for solving the multiple constrained resource project scheduling problem. Management Science, 30(7), 854-867.

Pellerin, R. \& Perrier, N. (2018). A review of methods, techniques and tools for project planning and control. International Journal of Production Research, 1-19.

Peng, W. \& Huang, M., 2014. A critical chain project scheduling method based on a differential evolution algorithm. International Journal of Production Research, 52(13), 3940-3949.

Petit, Y. (2012). Project portfolios in dynamic environments: Organizing for uncertainty. International Journal of Project Management 30(5), 539-553.

Petit, Y. \& Hobbs, B. (2010). Project portfolios in dynamic environments: sources of uncertainty and sensing mechanisms. Project Management Journal, 41 (4), 46-58.

Pich M.T., Loch C.H. \& De Meyer A. (2002). On uncertainty, ambiguity, and complexity in project management. Management Science, 48(8), 1008-1023.

Ranjbar, M. \& Davari, M. (2013). An exact method for scheduling of the alternative technologies in R\&D projects. Computers \& Operations Research, 40(1), 395-405. 
Rostami, S., Creemers, S. \& Leus, R., (2018). New strategies for stochastic resource-constrained project scheduling. Journal of Scheduling, 21, 349-365.

Sabuncuoglu, I., \& Goren, S. (2009). Hedging production schedules against uncertainty in manufacturing environment with a review of robustness and stability research. International Journal of Computer Integrated Manufacturing, 22(2), 138-157.

Schwindt, C. \& Zimmermann, J. (Editors) (2015). Handbook on Project Management and Scheduling Vol. 1\&2. Springer International Publishing, Switzerland.

Schwartz, E.S. \& Zozaya-Gorostiza, C. (2003). Investment under uncertainty in information technology: acquisition and development projects. Management Science, 49(1), 57-70.

Sobel, M. J., Szmerekovsky, J. G., \& Tilson, V. (2009). Scheduling projects with stochastic activity duration to maximize expected net present value. European Journal of Operational Research, 198(3), 697-705.

Shen, S., Smith, J.C. \& Ahmed, S. (2010). Expectation and chance-constrained models and algorithms for insuring critical paths. Management Science, 56(10), 1794-1814.

Shenhar, A. J. \& Dvir D. (1996). Toward a typological theory of project management. Research Policy, 25(4), 607-632.

Shenhar, A. (2001) One size does not fit all projects: Exploring classical contingency domains. Management Science, 47(3), 394-414.

Stork, F. (2001). Stochastic resource-constrained project scheduling. Ph.D. Thesis, Technische Universität Berlin.

Tareghian, H., Taheri, S. (2006). On the discrete time, cost and quality tradeoff problem. Applied Mathematics and Computation, 181, 1305-1312.

Tareghian, H., Taheri, S. (2007). A solution procedure for the discrete time, cost and quality tradeoff problem using electromagnetic scatter search. Applied Mathematics and Computation, 190, 11361145. 
Tavana, M., Abtahi, A.R. \& Khalili-Damghani, K. (2014). A new multi-objective multi-mode model for solving preemptive time-cost-quality trade-off project scheduling problems. Expert Systems with Applications, 41(4), 1830-1846.

Tavares L.V., Ferreira J.A.A. \& Coelho J.S. (1998). On the optimal management of project risk, European Journal of Operational Research, 107, 451-469.

Tereso, A. P., Araujo, M.M., \& Elmaghraby, S. E. (2004a). Adaptive resource allocation in multimodal activity networks, International Journal of Production Economics, 92, 1-10.

Tereso, A. P., Araujo, M.M., \& Elmaghraby, S. E. (2004b). The optimal resource allocation in stochastic activity networks via the electromagnetism approach. Ninth International Workshop on Project Management and Scheduling (PMS'04).

Tereso, A. P., Costa, L.A., Novais, R.A., \& Araujo, M.M., (2007). The optimal resource allocation in stochastic activity networks via the evolutionary approach: a platform implementation in Java. International Conference on Industrial Engineering and Systems Management (IESM 2007), (Proceedings: ISBN 978-7-89486-439-0), Beijing, China.

Tereso, A. P., Araujo, M.M., Mautinho, R.S., \& Elmaghraby, S. E. (2008). Project management multiple resources allocation, International Conference on Engineering Optimization (EngOpt 2008), (Proceedings: ISBN 978857650156-5), Rio de Janeiro, Brazil.

Tiwari, V., Patterson, J. H., \& Mabert, V.A., (2009). Scheduling projects with heterogeneous resources to meet time and quality objectives. European Journal of Operational Research, 193(3), 780-790.

Trietsch, D. (2006). Optimal feeding buffers for projects or batch supply chains by an exact generalization of the newsvendor result. International Journal of Production Research, 44(4), 627637.

Tsai, Y. W., \& Gemmill, D. D. (1998). Using tabu search to schedule activities of stochastic resourceconstrained projects. European Journal of Operational Research, 111(1), 129-141.

Tukel, O.I. \& Rom, W. O. (1997). Ensuring quality in resource constrained project scheduling, European Journal of Operational Research, 103(3), 483-496. 
Tukel, O.I. \& Rom, W. O. (2001). An empirical investigation of project evaluation criteria, International Journal of Operations and Production Management, 21(3), 400-416.

Tukel, O. I., Rom, W. O., Eksioglu, S. D. (2006). An investigation of buffer sizing techniques in critical chain scheduling. European Journal of Operational Research, 172(2), 401-416.

Vaagen, H., Kaut, M. \& Wallace, S.W (2017). The impact of design uncertainty in engineer-to-order project planning. European Journal of Operational Research, 261(3), 1098-1109.

Vale, J.W.S.P. \& Carvalho, M.M.D. (2017). Risk and uncertainty in projects management: literature review and conceptual framework. Revista GEPROS, 12(2), 93.

Valls, V., Ballestin, F., \& Quintanilla, S. (2005). Justification and RCPSP: A technique that pays. European Journal of Operational Research, 165(2), 375-386.

Van de Vonder, S., Demeulemeester, E., Herroelen, W. \& Leus, R. (2005). The use of buffers in project management: The trade-off between stability and makespan. International Journal of Production Economics; 97, 227-240.

Van de Vonder, S., Demeulemeester, E., Herroelen, W., Leus, R., (2006). The trade-off between stability and makespan in resource-constrained project scheduling. International Journal of Production Research, 44, 215-236.

Van de Vonder, S., Ballestin, F., Demeulemeester, E. \& Herroelen, W. (2007a). Heuristic procedures for reactive project scheduling. Computers \& Industrial Engineering, 52(1), 11-28.

Van de Vonder, S., Demeulemeester, E. \& Herroelen, W. (2007b). A classification of predictivereactive project scheduling procedures. Journal of Scheduling, 10(3), 195-207.

Van de Vonder S., Demeulemeester, E. \& Herroelen, W. (2008). Proactive heuristic procedures for robust project scheduling: An experimental analysis. European Journal of Operational Research,189(3), 723-733.

Wang, J. (2002). A fuzzy project scheduling approach to minimize schedule risk for product development. Fuzzy Sets and Systems, 127 (2), 99-116. 
Wang, J. (2004). A fuzzy robust scheduling approach for product development projects. European Journal of Operational Research, 152, 180-194.

Wang, X., \& Ning, Y. (2018). Uncertain chance-constrained programming model for project scheduling problem. Journal of the Operational Research Society, 69(3), 384-391.

Ward, S. \& Chapman, C. (2003). Transforming project risk management into project uncertainty management. International Journal of Project Management, 21(2), 97-105.

Ward, S., \& Chapman C. (2008). Stakeholders and uncertainty management in projects. Construction Management and Economics, 26 (6), 563-577.

Wiesemann, W., Kuhn, D. and Rustem, B., 2010. Maximizing the net present value of a project under uncertainty. European Journal of Operational Research, 202, 356-367.

Williams, T., Eden, C., Ackermann, F. \& Tait, A. (1995). The effects of design changes and delays on project costs. Journal of the Operational Research Society, 46(7), 809-818.

Xu, J., Zheng, H., Zeng, Z., Wu, S. \& Shen, M., 2012. Discrete time-cost-environment trade-off problem for large-scale construction systems with multiple modes under fuzzy uncertainty and its application to Jinping-II Hydroelectric Project. International Journal of Project Management, 30(8), 950-966.

Xu, X., Zhao, Y. \& Chen, C.Y., (2016). Project-driven supply chains: integrating safety-stock and crashing decisions for recurrent projects. Annals of Operations Research, 241(1-2), 225-247.

Yamashita, D.S., V.A. Armentano \& M. Laguna (2007), Robust optimization models for project scheduling with resource availability cost, Journal of Scheduling, 10, 67-76.

Yang, K.K. (1996). Effects of erroneous estimation of activity durations on scheduling and dispatching a single project, Decision Sciences, 27(2), 255-290.

Yang, I.T. (2005). Impact of budget uncertainty on project time-cost tradeoff, IEEE Transactions on Engineering Management, 52(2), 167-174. 
Yang, I.T. \& Chang, C.Y. (2005). Stochastic resource-constrained scheduling for repetitive construction projects with uncertain supply of resources and funding, International Journal of Project Management, 23, 546-553.

Yeo, K.T. \& J.H. Ning. 2006. Managing uncertainty in major equipment procurement in engineering projects, European Journal of Operational Research 171(1), 123-134.

Zareei, A., Zaerpour, F., Bagherpour, M., Noora, A.A.\& Vencheh, A.H., (2011). A new approach for solving fuzzy critical path problem using analysis of events. Expert Systems with Applications, 38(1), 87-93.

Zhang, Q., Huang, X. \& Tang, L., (2011). Optimal multinational capital budgeting under uncertainty. Computers \& Mathematics with Applications, 62(12), 4557-4567.

Zhang, J. \& Elmaghraby, S. (2014). The relevance of the "alphorn of uncertainty" to the financial management of projects under uncertainty, European Journal of Operational Research, 238(1), 65-76.

Zhang, J., Song, X., \& Díaz, E. (2016). Project buffer sizing of a critical chain based on comprehensive resource tightness. European Journal of Operational Research, 248(1), 174-182.

Zhang, J., Jia, S., \& Diaz, E. (2018). Dynamic monitoring and control of a critical chain project based on phase buffer allocation. Journal of the Operational Research Society, 1-12.

Zheng, W., He, Z., Wang, N., \& Jia, T. (2018). Proactive and reactive resource-constrained max-NPV project scheduling with random activity duration. Journal of the Operational Research Society, 69(1), 115-126.

Zhu, G., Bard, J.F. \& Yu, G. (2005). Disruption management for resource-constrained project scheduling, Journal of the Operational Research Society, 56, 365-381.

Zhu, G., Bard, J.F. and Yu, G. (2007). A two-stage stochastic programming approach for project planning with uncertain activity durations, Journal of Scheduling. 10, 167-180.

Zimmermann, H.J. 2001. Fuzzy Set Theory And Its Applications (4th ed.). Kluwer Academic Publishers, Boston. 